\title{
The tumor-promoting actions of TNF- $\alpha$ involve TNFR1 and IL-17 in ovarian cancer in mice and humans
}

\author{
Kellie A. Charles, ${ }^{1}$ Hagen Kulbe, ${ }^{1}$ Robin Soper, ${ }^{1}$ Monica Escorcio-Correia, ${ }^{1}$ \\ Toby Lawrence, ${ }^{1}$ Anne Schultheis, ${ }^{1}$ Probir Chakravarty, ${ }^{2}$ Richard G. Thompson, ${ }^{1}$ \\ George Kollias, ${ }^{3}$ John F. Smyth, ${ }^{4}$ Frances R. Balkwill, ${ }^{1}$ and Thorsten Hagemann' \\ ${ }^{1}$ Centre for Cancer and Inflammation, Institute of Cancer, Barts and The London School of Medicine and Dentistry, \\ Queen Mary University of London, London, United Kingdom. ${ }^{2}$ Bioinformatics and Biostatistics Service, Cancer Research UK, London, United Kingdom. \\ ${ }^{3}$ Biomedical Sciences Research Center “Al. Fleming," Vari, Greece. ${ }^{4}$ University of Edinburgh, Cancer Research Centre, Edinburgh, United Kingdom.
}

\begin{abstract}
Cytokines orchestrate the tumor-promoting interplay between malignant cells and the immune system. In many experimental and human cancers, the cytokine TNF- $\alpha$ is an important component of this interplay, but its effects are pleiotropic and therefore remain to be completely defined. Using a mouse model of ovarian cancer in which either TNF receptor 1 (TNFR1) signaling was manipulated in different leukocyte populations or TNF- $\alpha$ was neutralized by antibody treatment, we found that this inflammatory cytokine maintained TNFR1-dependent IL-17 production by $\mathrm{CD}^{+}$cells and that this led to myeloid cell recruitment into the tumor microenvironment and enhanced tumor growth. Consistent with this, in patients with advanced cancer, treatment with the TNF- $\alpha-$ specific antibody infliximab substantially reduced plasma IL-17 levels. Furthermore, expression of IL-1R and IL-23R was downregulated in $\mathrm{CD}^{+} \mathrm{CD}^{+} 5^{-}$cells isolated from ascites of ovarian cancer patients treated with infliximab. We have also shown that genes ascribed to the Th17 pathway map closely with the TNF- $\alpha$ signaling pathway in ovarian cancer biopsy samples, showing particularly high levels of expression of genes encoding IL-23, components of the NF- $\kappa$ B system, TGF- $\beta 1$, and proteins involved in neutrophil activation. We conclude that chronic production of TNF- $\alpha$ in the tumor microenvironment increases myeloid cell recruitment in an IL-17dependent manner that contributes to the tumor-promoting action of this proinflammatory cytokine.
\end{abstract}

\section{Introduction}

The tumor microenvironment generates a complex cytokine network that influences malignant cell proliferation, metastasis, angiogenesis, and the composition of the leukocyte infiltrate. This cytokine network also subverts adaptive immunity and alters response to hormones and chemotherapeutic agents $(1,2)$. In both murine and human cancers, cytokines such as TNF- $\alpha$, IL-6, IL-10, IL-17, IL-23, and TGF- $\beta$ are thought to be key mediators of this inflammatory protumor microenvironment (3-9).

The inflammatory cytokine TNF- $\alpha$ has a critical role in chronic inflammatory diseases such as rheumatoid arthritis (10), and its tumor-promoting role has been clearly demonstrated in mouse cancer models (11-16). In these models and in human cancers, TNF- $\alpha$ is produced by malignant and/or host cells within the tumor microenvironment $(11,14,17-23)$. The mechanisms of action of TNF- $\alpha$ in the tumor microenvironment are not fully elucidated but may include a central role in a cancer-cell autonomous tumor-promoting network of other cytokines and chemokines (20), stimulation of epithelial to mesenchymal transition in malignant cells (24), or further DNA damage to malignant cells (25). The actions of TNF- $\alpha$ on other cells in the tumor microenvironment include promotion of angiogenesis (20) that could be via induction of a proangiogenic

Authorship note: K.A. Charles, H. Kulbe, F.R. Balkwill, and T. Hagemann contributed equally to this work.

Conflict of interest: F.R. Balkwill has received funding and has in the past acted as a consultant for Centocor Inc., which supplies anti-TNF- $\alpha$ antibodies commercially. K.A. Charles was funded by Centocor Inc.

Citation for this article: J. Clin. Invest. 119:3011-3023 (2009). doi:10.1172/JCI39065 phenotype in recruited monocytes (26), impairment of immune surveillance through $\mathrm{T}$ cell suppression (27), and inhibiting the cytotoxicity of activated macrophages (28).

TNF- $\alpha$ binds to 2 receptors, the ubiquitously expressed TNF receptor 1 (TNFR1) and hematopoietically restricted TNFR2, to induce a signaling cascade that induces transcriptional regulation of mediators that are key to cell survival, invasion, angiogenesis, and impairment of immune surveillance in tumor biology $(18,20$, 27). Previously published studies suggest that TNFR1 is the major mediator of the tumor-promoting actions of TNF- $\alpha$ (29-31), although TNFR2 on Tregs may play a role (32). There is little information on the role of other $T$ cell subtypes in the tumor-promoting action of TNF- $\alpha$, and a detailed dissection of the action of TNF- $\alpha$ on different leukocyte subsets has not been performed so far.

Further proof of the tumor-promoting role of TNF- $\alpha$ comes from experiments showing that TNF- $\alpha$ antagonists, either antiTNF- $\alpha$ antibodies or TNF receptor fusion molecules, have antitumor activity in a range of mouse cancer models. These include 9,10-dimethylbenz(a)anthracene/12-O-tetradecanoylphorbol13-acetate-induced (DMBA/TPA-induced) skin cancer (33), genetic models of liver cancer (12) a carcinogen-induced model of colorectal cancer (13), and pancreatic cancer xenografts (14). These preclinical experiments with TNF- $\alpha$ antagonists and early-phase clinical trials of TNF- $\alpha$ antagonists in patients with advanced cancer $(18,34-36)$ suggest that this inflammatory cytokine may be a therapeutic target in malignant disease. As with the animal models, TNF- $\alpha$ would be expected to have direct tumor-promoting actions in cancer patients as well as suppressive effects on the immune system. 
A

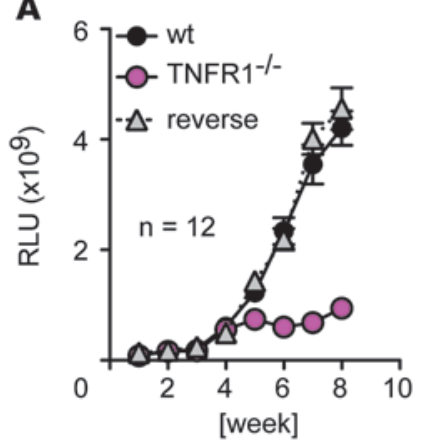

C

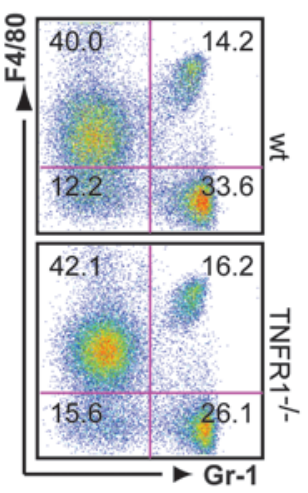

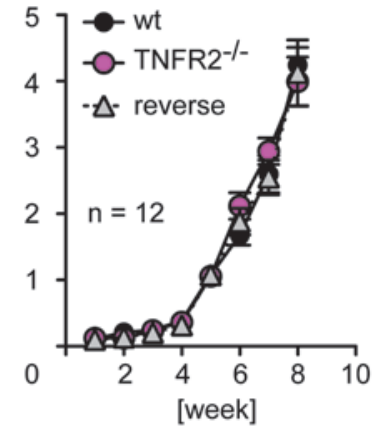

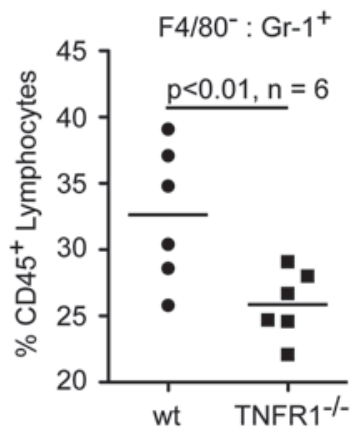

B

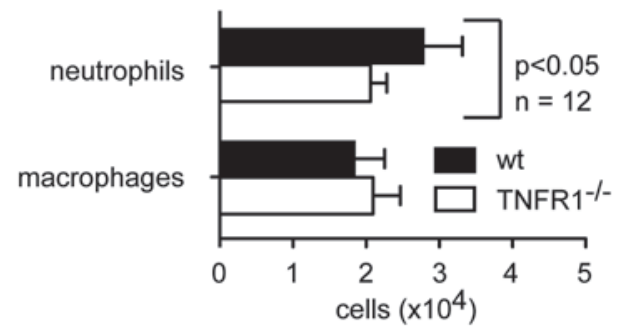

D

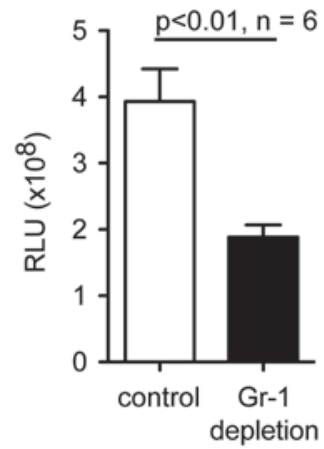

Figure 1

Disease stabilization in TNFR1 bone marrow chimeras. (A) TNFR1-- bone marrow, WT bone marrow, and reverse (WT bone marrow in TNFR1-l- mice) chimeras were i.p. injected with $10^{7}$ ID8 cells/mouse. Tumor burden was monitored weekly in situ by bioluminescence. TNFR1-1- bone marrow chimeras had significantly lower disease burden, starting 4 weeks after tumor cell injection $(P<0.01)$. Data are represented as mean \pm SEM of $n=12$. Representative data are shown from 2 independent experiments. (B) Total cell counts in the malignant ascites at week 8 . Cytospins were prepared from ascitic fluid, and cells were differentiated with Wright's staining. TNFR1 ${ }^{-l-}$ bone marrow chimeras had a significantly lower neutrophil infiltrate in the peritoneal cavity $(P<0.05, n=12)$. Data are represented as mean $\pm \mathrm{SD}$ of $n=12$. Representative data are shown from 2 independent experiments. Data for WT (control mice, no chimeras) and reverse chimeras are shown in Supplemental Figure 1. (C) FACS analysis of the ascitic leukocyte infiltrate. TNFR1-l- bone marrow chimeras had significantly fewer infiltrating $\mathrm{Gr}-1^{+} \mathrm{F} 4 / 80^{-}$neutrophils $(P<0.01, n=6)$. Data are represented as percentage of the CD45+ population, including mean of $n=6$. Representative data are shown from 2 independent experiments (week 8). (D) WT mice were injected with 107 ID8-luc cells i.p.; Gr-1-neutralizing antibody or IgG control antibody were commenced twice weekly i.p. (100 $\mu \mathrm{g} / \mathrm{mouse})$. Data are represented as mean $+\mathrm{SEM}$ of $n=6$. Representative data are shown from 2 independent experiments (week 8).

The aim of the work described here was to study the mechanisms of action of TNF- $\alpha$ in the tumor microenvironment using animal models in which TNFR1 signaling could be restored in specific cell populations or TNF- $\alpha$ inhibited by neutralizing antibody treatment and to relate our findings to human cancer patients treated with anti-TNF- $\alpha$ antibodies. We identified what we believe is a novel way in which TNF- $\alpha$ can orchestrate the tumor microenvironment. We show that TNF- $\alpha$ signaling, via the inflammatory cytokine IL-17, promotes tumor progression in a mouse model of advanced ovarian cancer and in patients with advanced cancer.

\section{Results}

The aim of our first experiments was to investigate the impact of TNF- $\alpha$ signaling on infiltrating leukocytes in the ID8 model of ovarian cancer. This syngeneic mouse model resembles advanced stage IV human ovarian cancer and is known to produce TNF- $\alpha$, as well as a range of other inflammatory cytokines, in the peritoneal tumor microenvironment (28). WT mice were lethally irradiated and reconstituted with bone marrow transplants from WT,
TNFR1 ${ }^{-/-}$, or TNFR2 ${ }^{-/-}$mice. We also generated reverse chimeras in which lethally irradiated TNFR1 $1^{-/}$mice received WT bone marrow. Chimeras were injected i.p. with luciferase-expressing ID8 ovarian cancer cells (ID8-luc), and tumor burden was monitored weekly in situ by bioluminescence. After 8 weeks growth in vivo, the tumor burden was significantly lower in chimeric mice reconstituted with TNFR1 $1^{-/-}$bone marrow compared with mice reconstituted with WT bone marrow or reverse chimeras (TNFR1 $1^{-/}$mice reconstituted with WT bone marrow) $(P<0.01)$ (Figure 1A). There was no difference in tumor burden compared with WT controls or reverse chimeras when WT mice were reconstituted with TNFR2 $2^{-/-}$bone marrow (Figure 1A). Additionally, we used TNFR1/2-/- doubleknockout mice to see whether the effects observed were caused by driving all responses to TNF- $\alpha$ through TNFR2. The results from the double-knockout mice mirrored the TNFR1-/- chimera results (Supplemental Figure 1A; supplemental material available online with this article; doi:10.1172/JCI39065DS1).

Analysis of the cellular composition of the ascites after 8 weeks of tumor growth revealed that TNFR $1^{-/-}$bone marrow chimeric mice had a significantly lower Gr-1+ $\mathrm{F} 4 / 80^{-}$leukocyte infiltrate 
A

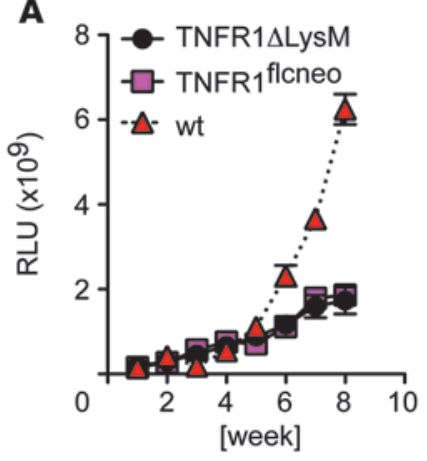

B

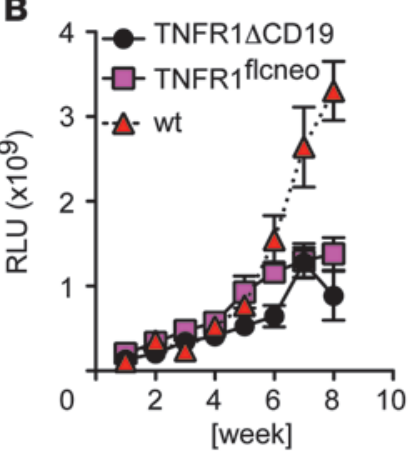

C
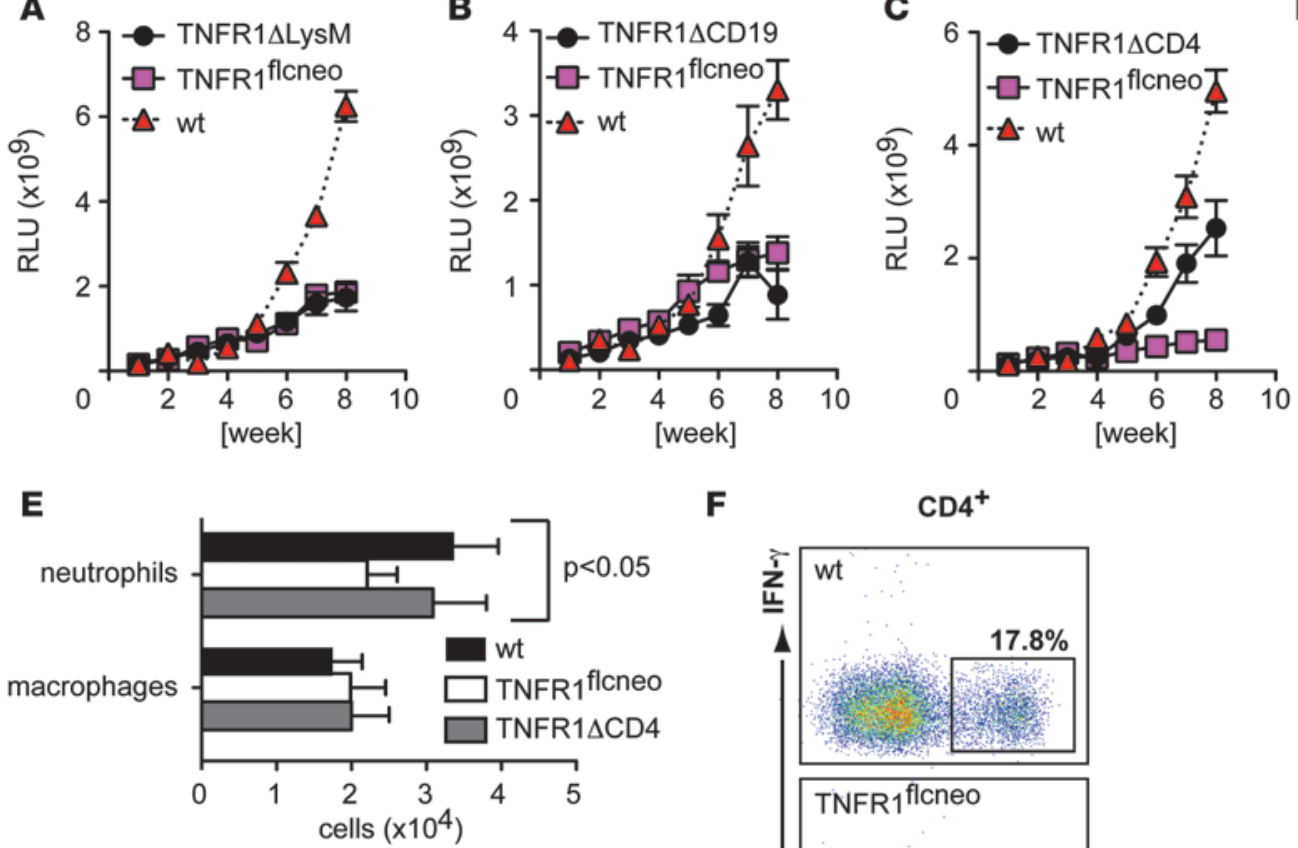

$\mathbf{F}$
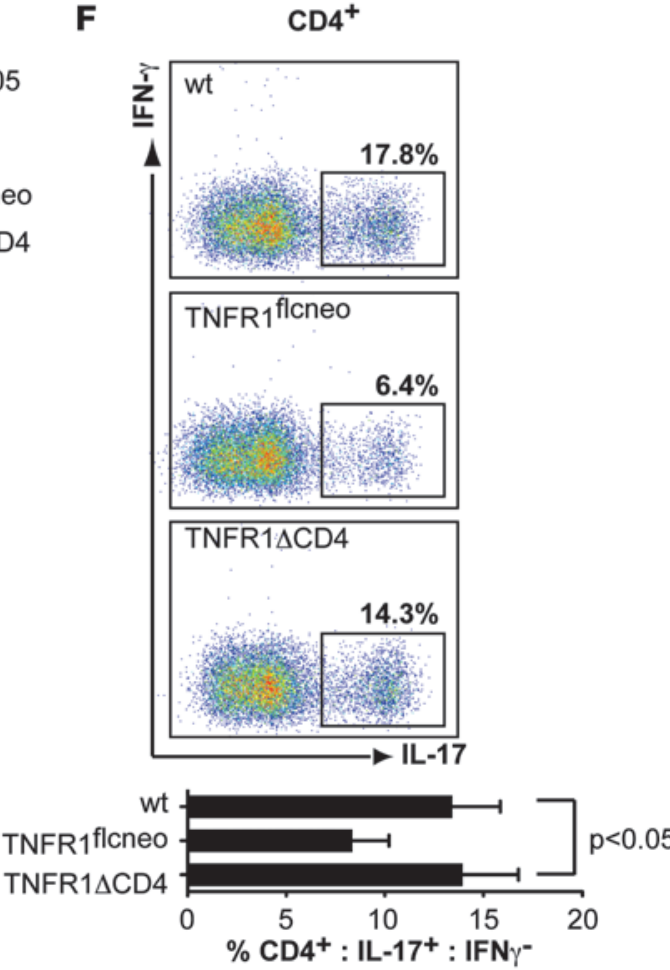

D

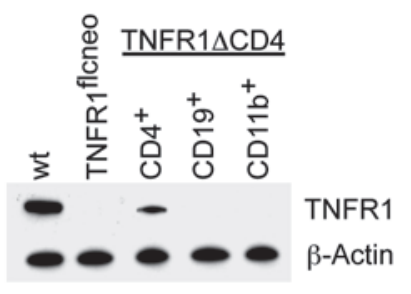

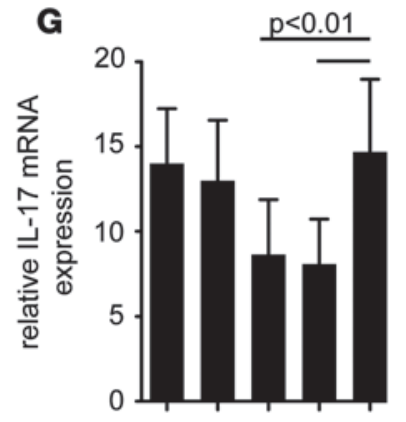

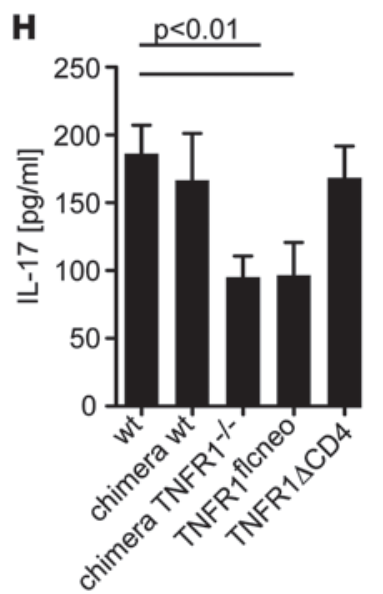

\section{Figure 2}

Tissue-specific reconstitution of TNFR1. Data are represented as mean \pm SEM of $n=6$. TNFR1flcneo mice had significantly lowered disease burden $(P<0.01)$ compared with WT mice. (A) TNFR1 gain of function in the monocyte/macrophage lineage has (TNFR1DLysM) no effect on tumor growth. (B) TNFR1 gain of function in CD19+ cells (TNFR1 $\triangle$ CD19) has no effect on tumor growth. (C) Gain of function of TNFR1 in the CD4 lineage of TNFR1 $\triangle$ CD4 mice "rescued" the protective effect of TNFR1 depletion. (D) Western blot for TNFR1 on protein lysates from CD4+ cells shows knockin of TNFR1 in CD4+ cells of TNFR1 $\triangle$ CD4+ mice but not CD19+ or CD11 b+ cells. (E) ID8 tumor-bearing TNFR1flcneo mice have significantly fewer neutrophils in the malignant ascitic fluid $(P<0.05$; compared with WT mice). This effect is reversed in TNFR1 $\triangle$ CD4 mice $\left(P<0.05\right.$; compared with $\left.T N F R 1^{f / c n e o}\right)$. Data are represented as mean $\pm \mathrm{SD}$ of $n=6$. (F) FACS analysis of the ascitic CD4+ population. TNFR1 ${ }^{f / c n e o}$ tumor-bearing mice have significantly fewer ascitic Th17 cells $(P<0.01, n=6)$ compared with WT and TNFR1 $\triangle$ CD4 mice. (G) IL-17 mRNA expression in $\mathrm{CD} 4^{+}$cells isolated from ascites of tumor-bearing mice at 8 weeks. (H) Ascitic CD4 ${ }^{+}$cells were selected and pooled $(n=3)$ and ex vivo stimulated with PMA and ionomycin for 4 hours. CD4+ cells from TNFR1-1- chimeras or TNFR flcneo mice secreted significantly lower amounts of IL-17 $(P<0.01)$. Data are represented as mean \pm SD of $n=6$. Representative data are shown from 2 independent experiments.

compared with WT chimeric mice $(P<0.05$, Figure 1 , B and C; Supplemental Figure $1 \mathrm{~B}$ shows all groups). This Gr-1+ $1^{+} 4 / 80^{-}$population was IL-4R $\alpha^{-}$(data not shown). We therefore concluded that TNFR1 mediated the tumor-promoting action of TNF- $\alpha$ through Gr-1 $1^{+} \mathrm{F} 4 / 80^{-}$cells in this cancer model. To confirm this, we depleted $\mathrm{Gr}-1^{+}$cells in tumor-bearing mice, which led to disease stabilization (Figure 1D).
Functional CD4 TNFR1 signaling is crucial for tumor progression. We next used a floxed TNFR1 knockin system (TNFR1flcneo) (37) to express TNFR1 in different leukocyte populations in C57BL/6 mice. TNFR $1^{\text {flcneo }}$ mice carry a conditional gain-offunction allele achieved by introducing a loxP-flanked neomycin-resistance cassette into intron 5 of the murine TNFRp55 gene (37). While TNFR1flcneo mice reflect TNFR1 $1^{-/-}$mice, the 

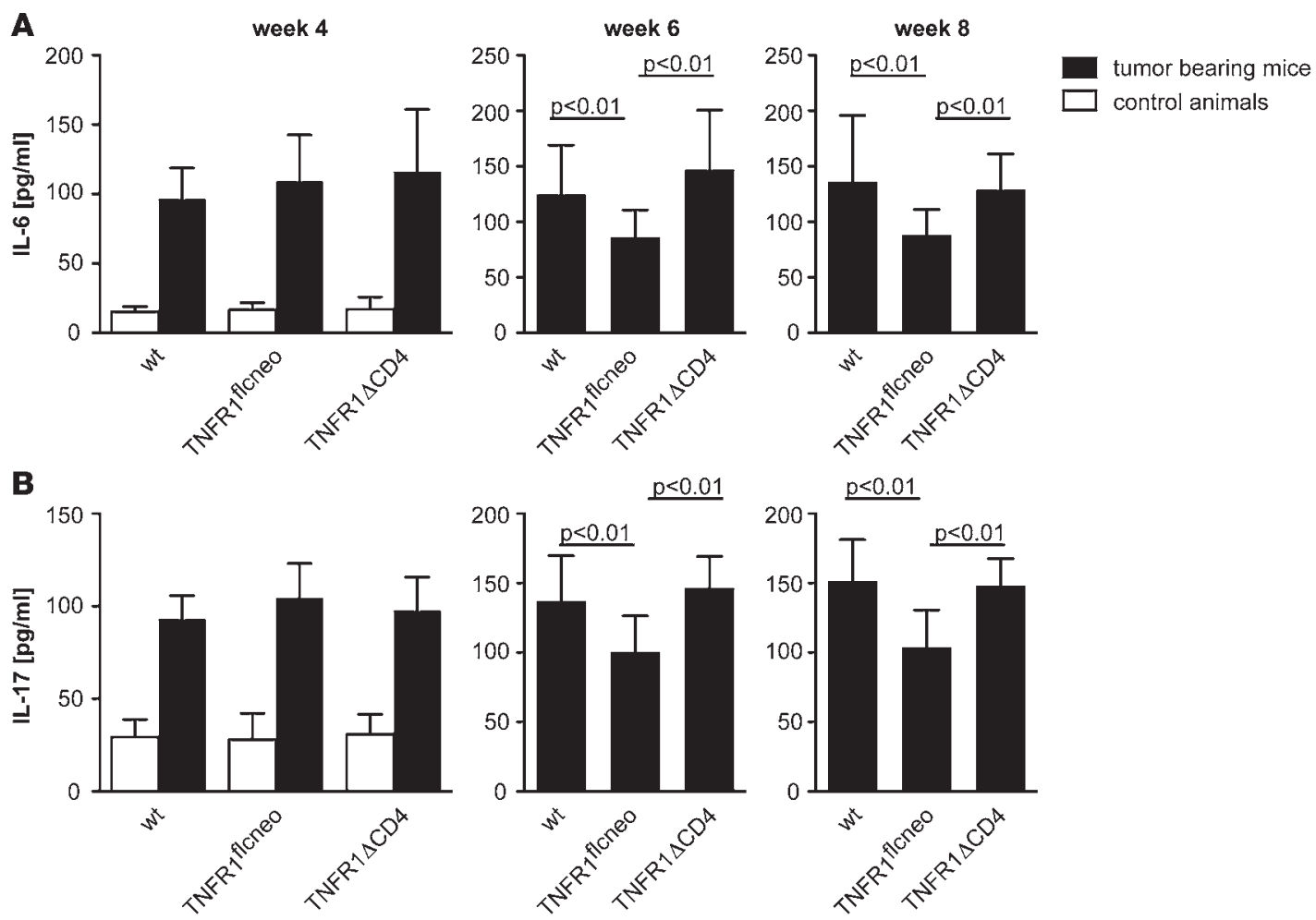

Figure 3

Analysis of cytokine expression during tumor progression in tumor-bearing mice at 4, 6, and 8 weeks. Mice were sacrificed and bled for plasma collection. (A) IL-6 analysis. (B) IL-17 analysis. Analysis showed no baseline difference (in non-tumor-bearing mice) for any of the analyzed cytokines (white bars in the 4-week graph). IL-6 and IL-17 levels are significantly lower in ID8 tumor-bearing mice 6 and 8 weeks after ID8 cell injection $(P<0.01, n=6)$. Data are represented as mean $+\mathrm{SD}$ of $n=6$. Representative data are shown from 2 independent experiments.

respective TNFR1 $\Delta$ mice gained TNFR1 function in different leukocyte populations.

Eight-week-old female WT, TNFR1 $\Delta$ LysM, TNFR1 $\Delta$ CD4, TNFR1 $\triangle$ CD19, and TNFR $1^{\text {flcneo }}$ mice were injected i.p. with ID8-luc cells, and peritoneal tumor growth was monitored weekly by bioluminescence. Tumor burden was significantly lower in TNFR1 1 LysM mice and TNFR $1^{\text {flcneo }}$ mice compared with WT mice (Figure 2A). Similarly, tumor growth was diminished in TNFR1 $\triangle$ CD19 mice (Figure 2B). However, gain of function for TNFR1 in CD4 cells restored tumor burden in TNFR1 $\triangle \mathrm{CD} 4$ mice to WT levels when compared with TNFR1 flcneo (Figure 2C) or the TNFR1 $1^{-/}$chimeric mice shown in Figure 1. The successful TNFR1 knockin in TNFR1 $\Delta$ CD4 mice is shown as a Western blot (Figure 2D).

To further understand the impact of TNFR1 signaling in CD4 cells, we investigated cellular changes in the ascitic microenvironment. We found no impact on the recruitment of macrophages into the ascitic fluid (Figure 2E). However, TNFR flcneo tumor-bearing mice had a significantly lower neutrophil infiltrate (Figure 2E) compared with WT or TNFR1 $1 \mathrm{CD} 4$ mice.

These experiments demonstrate that functional TNFR1 signaling on $\mathrm{CD}^{+}$cells is crucial for the tumor-promoting action of TNFR1 during peritoneal growth and spread in a model of advanced ovarian cancer and that Gr-1+ cells may be involved in the action of these cells.

TNF- $\alpha$ /TNFR1 signaling in CD4 cells is important for the Th17 cell subpopulation. Since TNF- $\alpha /$ TNFR1 signaling regulates many other cytokines and chemokines, we measured TNF- $\alpha$, IL-4, IL-6, IL-13,
IL-17, IL-23, TGF- $\beta$, CCL5, and KC in the malignant ascitic fluid of ID8 tumor-bearing mice. There was a significant increase of IL-17 at end point in the malignant ascites of WT (mean \pm SD: $143 \pm 64 \mathrm{pg} / \mathrm{ml}$ ) or TNFR1 $\triangle \mathrm{CD} 4($ mean \pm SD: $176 \pm 75 \mathrm{pg} / \mathrm{ml}$ ) mice compared with TNFR1 ${ }^{-/}$(mean \pm SD: $95 \pm 36 \mathrm{pg} / \mathrm{ml}$ ) or TNFR1 $1^{\text {flcneo }}$ mice (mean \pm SD: $\left.103 \pm 38 \mathrm{pg} / \mathrm{ml}\right)(P<0.05)$. We therefore focused on the $\mathrm{CD} 4^{+} \mathrm{Th} 17 \mathrm{~T}$ cell subset producing IL-17, but not IFN- $\gamma$, because IL-17 has been identified as an important player in inflammatory responses and cancer (38).

We analyzed $\mathrm{CD} 4^{+}$cells from the ascites of tumor-bearing WT, TNFR1 ${ }^{\text {flcneo }}$, and TNFR1 $\triangle$ CD 4 mice for IL-17 and IFN- $\gamma$ expression by FACS (Figure $2 \mathrm{~F}$ ). CD4 $4^{+}$cells with intact TNFR1 signaling from ID8 tumor-bearing WT or TNFR1 $\triangle$ CD 4 mice had significantly more $\mathrm{CD} 4^{+} \mathrm{IL}-17^{+} \mathrm{IFN}-\gamma^{-}$cells than $\mathrm{CD} 4^{+}$cells from TNFR $1^{\text {flcneo }}$ mice in which TNFR1 signaling was deficient (Figure 2F). There were no differences in Th17 cells in spleens of tumor-bearing mice or control non-tumor-bearing mice (data not shown); additionally, we did not see differences in $\mathrm{CD} 4^{+} \mathrm{CD} 25^{+}$cells in these mice (Supplemental Figure 2).

Next, we isolated ascitic $\mathrm{CD}^{+}{ }^{+}$cells from tumor-bearing mice for RNA analysis and for ex vivo stimulation with phorbol myristate acetate (PMA). TNFR1-deleted CD4 ${ }^{+}$cells from ID8 tumor-bearing mice expressed significantly lower amounts of IL-17 mRNA compared with WT mice and TNFR1 $\triangle \mathrm{CD} 4$ mice (Figure $2 \mathrm{G}$ ). We also stimulated ascitic $\mathrm{CD} 4^{+}$cells ex vivo with PMA to measure IL-17 protein secretion. TNFR $1^{-} \mathrm{CD} 4^{+}$cells from tumor-bearing mice secrete significantly lower amounts of IL-17 ex vivo than 


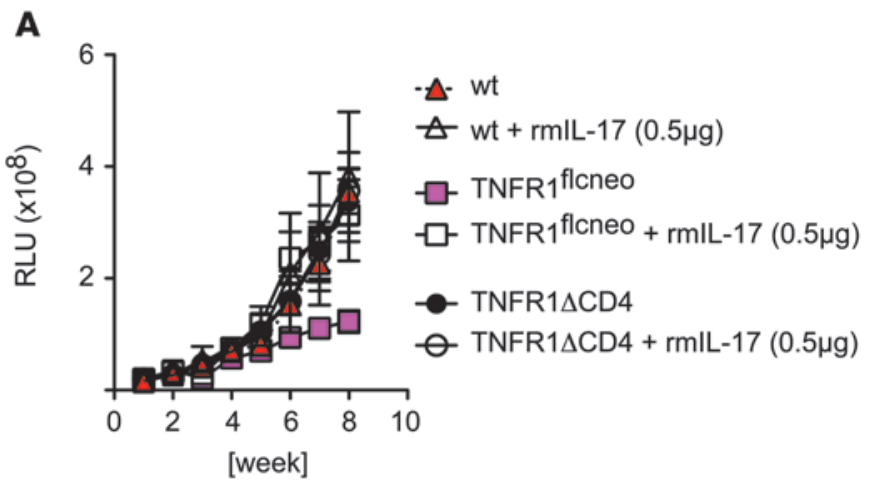

B

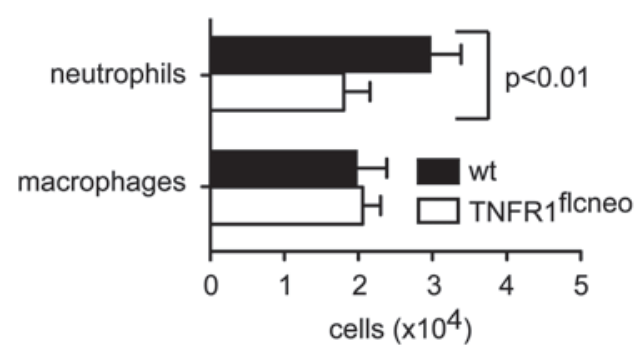

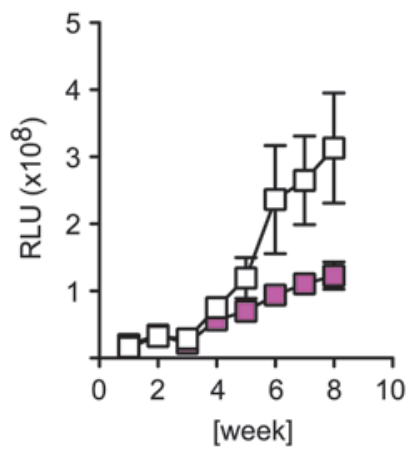

+ rmlL-17

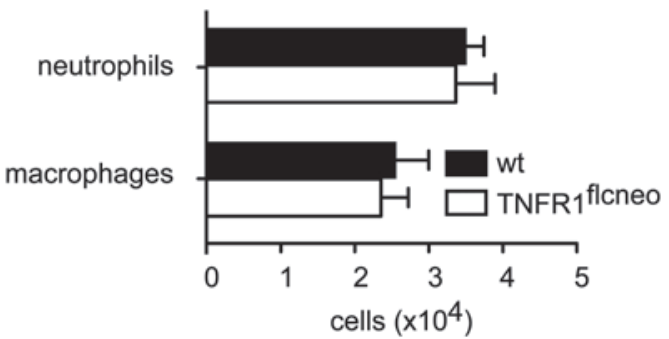

\section{Figure 4}

Increased IL-17-dependent neutrophil recruitment. (A) Recombinant IL-17 rescued the antitumor effect in TNFR1 $1^{\text {flcneo }}$ mice $(P<0.01)$. Data are represented as mean \pm SEM of $n=6$. Representative data are shown from 2 independent experiments. The right-hand graph demonstrates the curves for only TNFR1 1 cneo mice with or without recombinant IL-17. (B) Total cell counts of the leukocyte infiltrate in the malignant ascites at week 8 (after i.p. injection). Control (left): significantly lower neutrophils in TNFR1 flcneo ID8 tumor-bearing mice compared with WT mice $(P<0.01)$. Treatment with recombinant murine IL-17A $(0.5 \mu \mathrm{g} / \mathrm{mouse} /$ week; right): recombinant IL-17A rescued neutrophil infiltration in TNFR1 flcneo ID8 tumor-bearing mice. Data are represented as mean $+\mathrm{SD}$ of $n=6$. Representative data are shown from 2 independent experiments.

those from WT or TNFR1 $\triangle \mathrm{CD} 4$ tumor-bearing mice (Figure $2 \mathrm{H}$ ). We conclude that CD4 TNFR1 signaling leads to an increase in IL-17 in tumor-bearing mice.

Plasma cytokine profile during tumor progression in mice. We then measured plasma levels of key cytokines involved in Th1, Th2, and Th17 subpopulation development and maintenance (IL-1, IL-4, IL-6, IL-17, IL-23, TGF- $\beta$ ) during 4 to 8 weeks of ID8 tumor growth, the time when growth was maximal in control mice and mice with TNFR1 on their CD4 ${ }^{+} \mathrm{T}$ cells. Four weeks after tumor cell injection, there were no differences in plasma levels of IL- 6 and IL-17 between WT, TNFR1 $1^{\text {flneo }}$, and TNFR1 $\triangle$ CD 4 mice (Figure 3, A and B). Plasma levels of IL-1, IL-4, IL-23, TGF- $\beta$, and CCL5 did not differ among WT, TNFR1 $1^{\text {flcneo }}$, and TNFR1 $\triangle \mathrm{CD} 4$ tumor-bearing mice (data not shown); however, at weeks 6 and 8 there was a significant decrease in IL-6 (Figure 3A) and IL-17 (Figure 3B) levels in the TNFR $1^{\text {flcneo }}$ mice compared with TNFR1 $\triangle \mathrm{CD} 4$ mice.

IL-17 mediates $\mathrm{Gr}-1^{+} \mathrm{F} 4 / 80^{-}$cell recruitment into the ascitic tumor microenvironment. Of particular interest was the significant decrease in Gr- $1^{+}$myeloid cells in the ascites from TNFR $1^{\text {flcneo }}$ mice $(P<0.05$; Figure 2D). It had been demonstrated that IL-17 is capable of selectively recruiting neutrophils into the peritoneal cavity (39). To determine whether IL-17 is crucial for Gr- $1^{+} \mathrm{F} 4 / 80^{-}$recruitment in our model of stage IV ovarian cancer, we treated the mice twice weekly with recombinant murine IL-17A ( $0.5 \mu \mathrm{g} /$ mouse i.p.) (Figure 4A). Consistent with the previous results, TNFR $1^{\text {flcneo }}$ mice showed significantly decreased tumor burden compared with WT or TNFR1 $\triangle$ CD4 mice (Figure 4A). Treatment with recombinant IL-17A rescued this effect and increased tumor growth in TNFR $1^{\text {flcneo }}$ mice (Figure 4A). Analysis of the ascitic microenvironment demonstrated that recombinant IL-17A injections into TNFR $1^{\text {flcneo }}$ mice increased the influx of Gr- $1^{+} \mathrm{F} 4 / 80^{-}$cells $(P<0.01$; Figure 4B).

Anti-TNF- $\alpha$ treatment in the ID 8 ovarian cancer model. We next investigated whether treatment of ID8 tumor-bearing mice with a neutralizing anti-mouse TNF- $\alpha$ antibody $(50 \mu \mathrm{g} /$ mouse/twice weekly) influenced IL-17 levels, Gr- $1^{+}$F4/80- cell recruitment into the peritoneal tumor microenvironment, and tumor growth. Anti-TNF- $\alpha$-treated mice had a significantly lower disease burden compared with mice treated with IgG control antibody or PBS-treated mice $(P<0.01$; Figure 5A). After 8 weeks of tumor growth, plasma and ascitic IL-17 levels were significantly lower in the anti-TNF- $\alpha$-treated mice compared with PBS- or IgG control antibody-treated animals $(P<0.01$; Figure $5 \mathrm{~B})$. Additionally we found that plasma IL-6 levels (week 8 , end point) were significantly lower in the TNFR1 $1^{\text {flcneo }}$ mice (Figure 3A) and were also significantly $(P<0.05)$ reduced in the anti-TNF- $\alpha$-treated group (mean \pm SD: $95.5 \pm 48.6 \mathrm{pg} / \mathrm{ml}$ ) compared with the PBS$(142.11 \pm 64.2 \mathrm{pg} / \mathrm{ml})$ or IgG-treated group $(129.2 \pm 51.6 \mathrm{pg} / \mathrm{ml})$. However, there was no difference in the cytokine levels of IL-1, IL-4, IL-23, TGF- $\beta$, or CCL5 (data not shown). The Gr-1+ F4/80- cell infiltrate in the ascitic microenvironment was also significantly lower in the anti-TNF- $\alpha$-treated animals $(P<0.05$; Figure $5, \mathrm{C}$ and $\mathrm{E})$ compared with control groups as was the number of ascitic CD $4^{+}$IL- $17^{+}$IFN- $\gamma^{-}$Th17 cells (Figure $5 \mathrm{D}$ ), although there was no difference in the splenic CD $4^{+} \mathrm{IL}-17^{+} \mathrm{IFN}-\gamma^{-}$subset. Therefore, anti-TNF- $\alpha$ antibody treatment had effects similar to those of targeting TNFR1 in a cell-specific manner. 


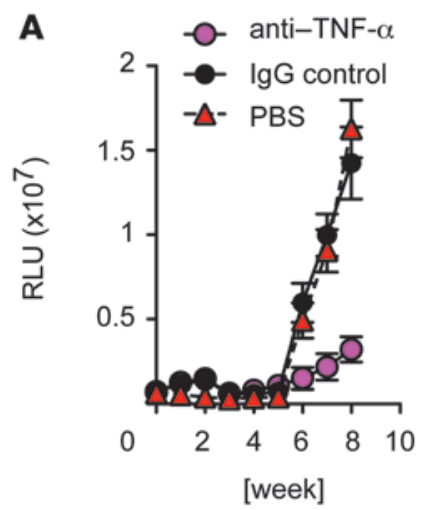

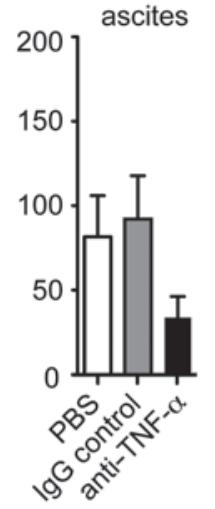

E

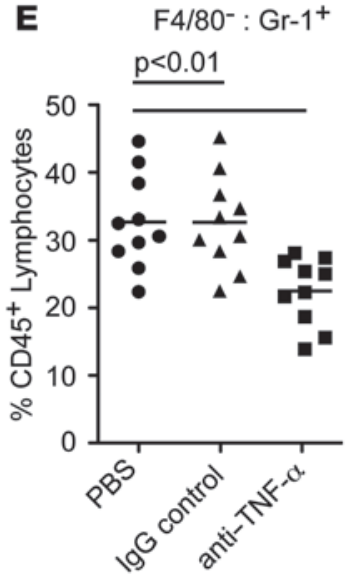

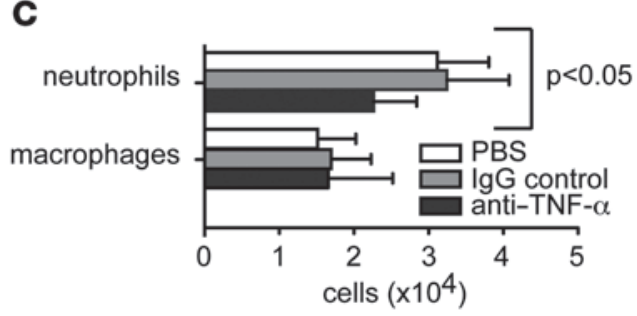

$\mathbf{F}$

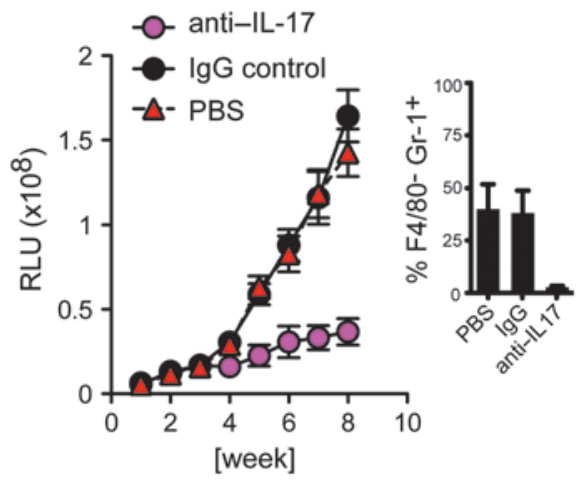

Figure 5

In vivo treatment with murine anti-TNF- $\alpha$ in a preclinical model of stage 4 ovarian cancer. (A) Neutralizing TNF- $\alpha$ antibody (50 $\mu \mathrm{g} / \mathrm{mouse})$ administered twice weekly led to disease stabilization in ID8 tumor-bearing mice $(P<0.01)$. Data are represented as mean $\pm \mathrm{SEM}$ of $n=10$. (B) IL-17 plasma and ascites levels (8-week time point). Anti-TNF- $\alpha$-treated mice had significantly lower IL-17 levels $(P<0.01)$. Data are represented as mean $\pm \mathrm{SD}$ of $n=10$. (C) Ascitic leukocyte infiltration. Within the ascitic fluid of anti-TNF- $\alpha$-treated mice were significantly fewer neutrophils $(P<0.05$; anti-TNF- $\alpha$ vs. IgG control, anti-TNF- $\alpha$ vs. PBS). Data are represented as mean + SD of $n=10$. (D) FACS analysis of the CD4+ subpopulation within ID8 tumor-bearing mice. Anti-TNF- $\alpha$ treatment led to a significant reduction in the CD4+IL-17+IFN $\gamma^{-}$population compared with control IgG- or PBS-treated mice. Data are represented as mean + SD of $n=10$. (E) FACS analysis of the Gr-1+ F4/80- population in the ascitic fluid. Significant reduction of neutrophils in the anti-TNF- $\alpha$-treated group. Data are represented as percentage of the CD45 ${ }^{+}$population including mean \pm SD of $n=10$. (F) Neutralizing IL-17A antibody (100 $\mu \mathrm{g} / \mathrm{mouse}$ ) administered twice weekly led to neutrophil depletion (insert) and disease stabilization in ID8 tumor-bearing mice $(P<0.01)$. Data are represented as mean \pm SEM of $n=10$. Representative data are shown from 2 independent experiments.

To demonstrate the relevance of IL-17 for tumor promotion, we used a neutralizing antibody for IL-17. Mice treated with neutralizing anti-IL-17 but nor IgG control or PBS showed a significant reduction in disease progression $(P<0.01$; Figure $5 \mathrm{~F})$. Sentinel mice were killed after 1 week of anti-IL-17 treatment, prior to tumor cell injection, to demonstrate efficient $\mathrm{GR} 1^{+} \mathrm{F} 4 / 80^{-}$cell depletion (Figure 5F).

Our results so far suggest that $\mathrm{CD} 4^{+}$TNFR1 signaling contributes to disease progression via IL-17 and recruitment of Gr-1 $1^{+}$ F4/80- cells to the tumor microenvironment. An anti-TNF- $\alpha$ antibody inhibits the same pathway in this mouse model of ovarian cancer. To investigate the correlation between TNF- $\alpha$ and IL-17 further and its relevance to human cancer, we studied plasma samples from cancer patients who had been treated with an antihuman TNF- $\alpha$ antibody, infliximab.

Infliximab reduces IL-17 plasma levels in patients with advanced malignant disease. In a phase I clinical trial, we reported that infliximab anti-TNF- $\alpha$ antibody treatment of patients with advanced cancer significantly reduced plasma IL-6 levels (36). In view of the above animal data, we measured IL-1, IL-4, IL-17, IL-23, and TGF- $\beta$, and CCL5 by ELISA in the plasma samples from this trial. IL-1, IL-4, IL-23, TGF- $\beta$, and CCL5 levels were all above detection levels, but there were no significant differences between pretreatment and 24-hour posttreatment samples (data not shown). However, in all patients studied $(n=40)$, plasma IL-17 levels were significantly lower 24 hours after infliximab infusion $(P<0.05$; Figure 6, A and B) compared with pretreatment samples.

In this trial, blood samples were also taken for the whole-blood cytokine release assay. This is a surrogate marker of biologic response to the antibody and involves short-term culture of whole blood with phytohemagglutinin (PHA) and analysis of cytokine production. Anti-TNF- $\alpha$ treatment significantly decreased production of IL-6 and IL-17 in cultures of the patients (Figure 6, C and D). There were no differences in IL-1, IL-4, IL-23, TGF- $\beta$, and CCL5 production (data not shown). 
A

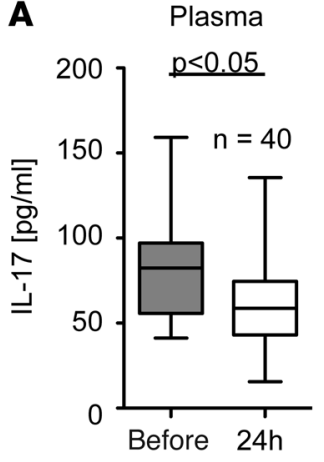

B

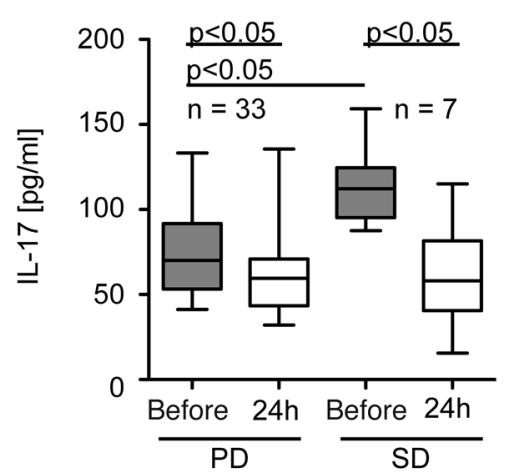

C

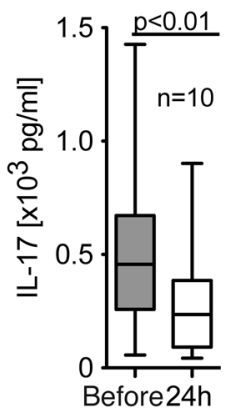

D

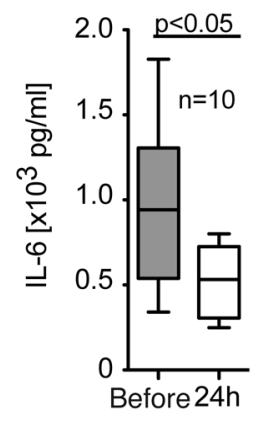

\section{Figure 6}

Patients with advanced malignancies treated with anti-TNF- $\alpha$ in phase I clinical trial. (A) 40 patients with a variety of malignancies were treated in a phase I/II clinical trial with infliximab (36). Plasma analysis before and 24 hours after treatment with infliximab demonstrated that anti-TNF- $\alpha$ significantly reduced the plasma levels of IL-17 $(P<0.05)$. Data are represented as mean \pm SD of $n=40$. (B) Analysis of IL-17 levels in stable $(\mathrm{SD})$ versus progressive disease $(\mathrm{PD})$ patients $(P<0.05)$. In both groups, IL-17 levels dropped significantly 24 hours after anti-TNF- $\alpha$ treatment. Data are represented as mean \pm SD of $n=40$. (C) Cytokine release assay: whole-blood samples were collected from patients in the presence of PHA. IL-17 release was significantly lower 24 hours after anti-TNF- $\alpha$ treatment $(P<0.05)$. Similar results were obtained for $\mathbf{D}$. IL-6 $(P<0.05)$.

Infliximab treatment of patients with advanced ovarian cancer. We also examined samples from 15 additional patients with advanced ovarian cancer and ascites who had been treated with infliximab. Both blood and ascitic fluid were obtained prior to and during infliximab treatment, and paracentesis samples from 3 ovarian cancer patients who had no anti-TNF- $\alpha$ antibody treatment were used as controls for ascites samples. In all patients, infliximab treatment reduced the blood and ascitic TNF- $\alpha$ concentrations 1 hour and 24 hours after the end of the 2-hour infliximab infusion (Figure 7A). Paracentesis alone had no effect on ascitic cytokine levels (TNF- $\alpha$ in control patients, mean \pm SD: before, $125 \pm 51 \mathrm{pg} / \mathrm{ml}$; 24 hours after, $142 \pm 74 \mathrm{pg} / \mathrm{ml}$ ).

There was no difference in plasma IL-17 levels before and after treatment in the infliximab-treated patients (Figure 7B); however, ascitic IL-17 levels were significantly lower 24 hours after treatment with infliximab $(P<0.05$; Figure 7B). Again, paracentesis alone did not affect IL-17 levels (IL-17 in control patients, mean \pm SD: before, $143 \pm 39 \mathrm{pg} / \mathrm{ml}$; 24 hours after, $162 \pm 42 \mathrm{pg} / \mathrm{ml}$ ).

Ascites cell samples were available from 15 of the treated patients and 3 control untreated patients. We extracted RNA from these and observed downregulation of TNF- $\alpha$ mRNA expression by realtime PCR when pretreatment samples were compared with posttreatment samples $(P<0.01$; Figure $7 \mathrm{C})$. IL-17 levels were significantly lower in total RNA from ascitic cells from treated but not control patients $(P<0.01$; Figure $7 \mathrm{~B})$ at the 24-hour time point. Since there was a presence of Th17 cells and expression of IL-17, we analyzed other Th17 cytokines such as IL-17F, IL-21, and IL-22 in these plasma and ascites samples (Supplemental Figure 3). There was no difference in plasma or ascitic IL-17F levels before and after treatment in the infliximab-treated patients (Supplemental Figure 3A); ascitic IL-21 levels were significantly lower 24 hours after treatment with infliximab (Supplemental Figure 3B); IL-22 levels were significantly reduced in ascites samples (Supplemental Figure 3C), showing that other Th17 cytokines were also regulated upon infliximab treatment.

As with the phase I trial, there were no differences in IL-1, IL-4, IL-23, TGF- $\beta$, or CCL5 levels after anti-TNF- $\alpha$ treatment in plasma or the whole-blood cytokine release assay (data not shown), but infliximab treatment significantly decreased production of IL- 6 and IL-17 in the whole-blood cytokine release assay (Figure 7, E and F).

Next, we isolated RNA from sorted ascitic CD4 ${ }^{+} \mathrm{CD} 25^{-}$cells and analyzed the expression of characteristic Th17 genes before and 24 hours after infliximab. Analysis revealed a significant reduction of IL17, IL22, CCR4, and CCR6; additionally receptor tyrosine kinase-like orphan receptor 2 (ROR2) was downregulated (Figure $7 \mathrm{G}$ ). Interestingly, IL-1R $\alpha$ and IL-23R were also significantly downregulated in these $\mathrm{CD} 4^{+} \mathrm{CD} 25^{-}$cells after infliximab treatment (Figure 7G). There was no difference in CCL20, IL-6, or IFN- $\gamma$ expression 24 hours after infliximab infusion. Infliximab treatment decreased IL- 6 production by peripheral blood cells; however, anti-TNF- $\alpha$ had few effects on IL- 6 mRNA expression by $\mathrm{CD} 4^{+} \mathrm{CD} 25^{-}$lymphocytes.

We postulated that TNF- $\alpha$ sensitizes T cells to Th17-promoting cytokines such as IL-1 and IL-23 by upregulation of the respective receptor. Therefore, we isolated $\mathrm{CD} 4^{+} \mathrm{CD} 25^{-} \mathrm{T}$ cells from the spleen of WT, TNFR1 $1^{-/}$, and TNFR2 $2^{-/-}$tumor-bearing mice and stimulated them with recombinant TNF- $\alpha$ to measure IL-1R $\alpha$ and IL-23R expression by real-time PCR. TNF- $\alpha$ did not upregulate IL-1R $\alpha$ and IL-23R in TNFR1 $1^{-/-} \mathrm{CD} 4^{+} \mathrm{CD} 25^{-} \mathrm{T}$ cells but did have an effect on WT and TNFR2-/- cells (Supplemental Figure 4).

TNF- $\alpha$ induces a network of $I L-17$-regulated genes in ovarian cancer patients. These results from 2 clinical trials of an anti-TNF- $\alpha$ antibody had parallels with the data obtained from the mouse model and suggest a role for IL-17 in the protumor actions of TNF- $\alpha$. We used a bioinformatics approach to further investigate the link between TNF- $\alpha$ and IL-17 in the tumor microenvironment. We analyzed the publicly available gene expression data set GSE9899 (Gene Expression Omnibus accession number) containing 285 human ovarian cancer biopsies profiled on the Affymetrix Human Genome U133plus2 platform. The inflammatory gene set of the canonical TNF- $\alpha$ signaling pathway was extracted from the GeneGo Metacore pathway analysis tool. Gene symbols were mapped to representative probes on the microarray chip, which were used to test enrichment using the function "genesettest" within the limma package. 
A
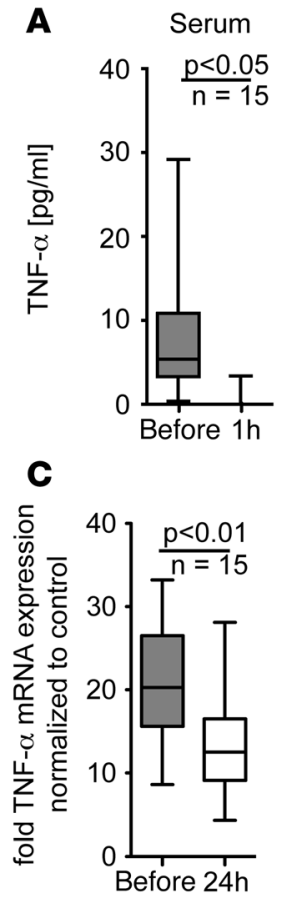

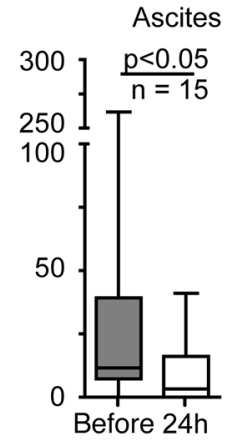

D

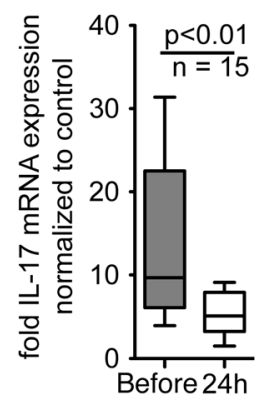

B

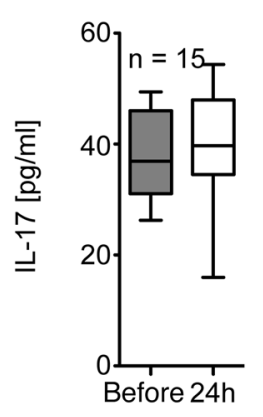

E

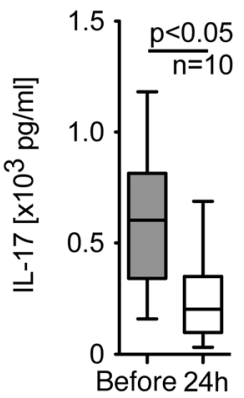

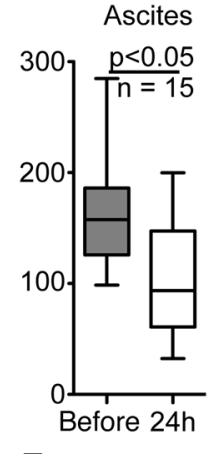

$\mathbf{F}$

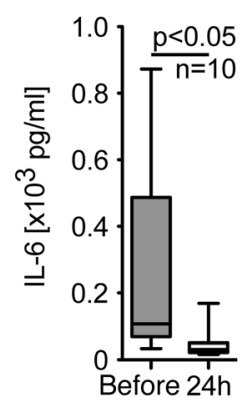

G ascitic CD4+CD25- sorted cells
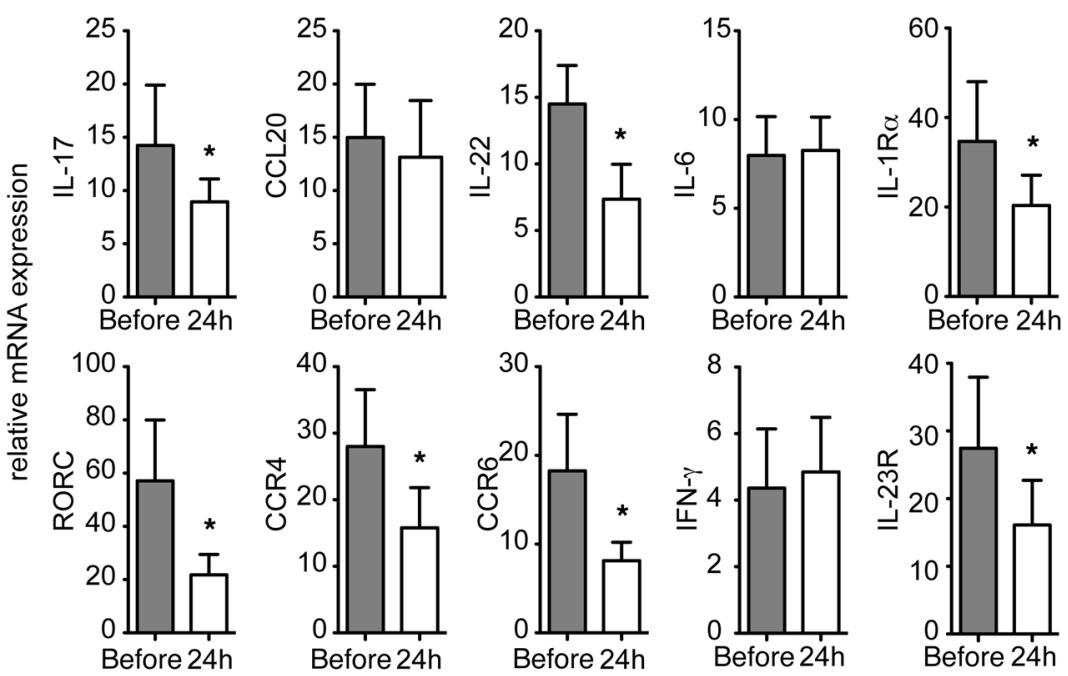

Figure 7

Ovarian cancer patients with advanced disease treated with infliximab in a phase I/II clinical trial. Seventeen patients with advanced ovarian cancer received i.v. anti-TNF- $\alpha$ treatment in this clinical study. (A) TNF- $\alpha$ concentrations $(P<0.05)$ were significantly lower at 1 hour (serum) and 24 hours (ascitic fluid) after infliximab infusion. Data are presented as mean \pm SD of $n=17$. (B) IL-17 protein levels were significantly reduced in the ascitic fluid 24 hours after infliximab infusion $(P<0.05)$; however, there was no difference in IL-17 plasma levels. Data are represented as mean \pm SD of $n=15$. (C) TNF- $\alpha$ real-time analysis of ascitic cell total RNA. TNF- $\alpha$ gene expression was significantly reduced 24 hours after anti-TNF- $\alpha$ treatment $(P<0.01)$. Data are represented as mean \pm SD of $n=15$. (D) IL-17 real-time analysis of ascitic cell total RNA. IL-17 gene expression was significantly reduced 24 hours after anti-TNF- $\alpha$ treatment $(P<0.01)$. Data are represented as mean $\pm \mathrm{SD}$ of $n=15$. ( $E$ and $\mathbf{F}$ ) Cytokine release assay: whole-blood samples were collected from patients in the presence of PHA. Cytokine release was measured by ELISA. IL-17 release was significantly lower 24 hours after anti-TNF- $\alpha$ treatment (E; $P<0.05)$; similar results were obtained for IL-6 (F; $P<0.05)$. (G) CD4 ${ }^{+}$CD25- cells were purified by FACS sorting following MACS bead isolation from ascites samples before treatment and 24 hours after infliximab infusion. Control naive CD4 ${ }^{+}$CD25- T cells were selected from peripheral blood of healthy blood donors. Data are represented as mean + SD of $n=10 ;{ }^{*} P<0.01$.
We ranked the 285 samples from this data set from low to high levels of gene expression in the TNF- $\alpha$ signaling pathway. As these biopsies may have variable proportions of malignant and stromal cells that might obscure/dilute any associations, we conducted our further analysis on the 50 samples with the highest expression of genes in the TNF- $\alpha$ signaling pathway and the 50 samples with the lowest expression of these genes. We obtained a list of genes that were statistically different between these 2 groups of samples (Student's $t$ test) and performed Gene Set Enrichment Analysis (GSEA; http://www. broadinstitute.org/gsea/) using Metacore pathway and process gene set analysis.

There was a significant association between high TNF- $\alpha$ signaling pathway gene expression and expression of genes in the "cytokine production in Th17 cells" pathway $\left(P=1.004^{-5}\right)$, with the "immune suppression" pathway $\left(P=1.351^{-8}\right)$ and "neutrophil acti- vation" pathway $\left(1.655^{-28}\right)$. Network objects (or genes) that make up the pathway "cytokine production in Th17 cells" were used to draw the heat map shown in Figure 8. This clearly shows that the genes ascribed to the Th17 pathway map closely with high levels of genes in the TNF- $\alpha$ signaling pathway in ovarian cancer biopsy samples, and this is particularly striking for CD14, ICAM1, IL-8, IL-23, genes of the NF-KB system, and TGF- $\beta 1$.

\section{Discussion}

In the present study, we dissected the tumor-promoting role of TNF- $\alpha$ in the microenvironment. We demonstrate for what we believe is the first time that TNF- $\alpha$ /TNFR1 signaling in $\mathrm{CD}_{4}^{+}$cells promotes malignant disease in a syngeneic murine model of ovarian cancer. Neutralizing TNF- $\alpha$ activity mimicked our findings in this model and also in patients with advanced cancer who were treated with the anti-TNF- $\alpha$ therapeutic antibody infliximab. 


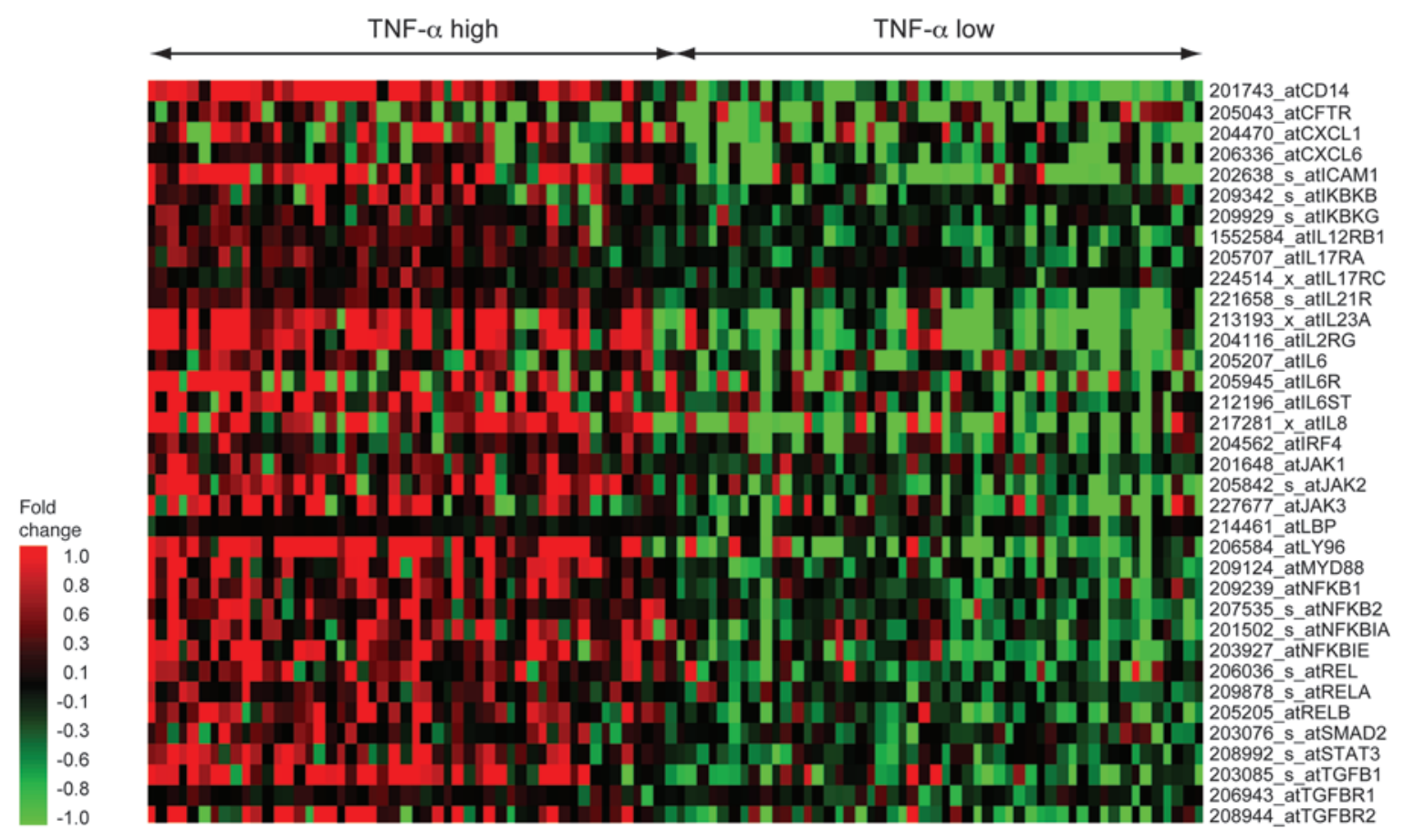

Figure 8

Gene array analysis. 285 samples of ovarian cancer data sets were ranked from low to high levels of gene expression in the TNF signaling pathway. The 50 samples with the highest expression of genes in this individual pathway and 50 samples with the lowest expression of these genes were analyzed. Network objects (or genes) that make up the pathway "cytokine production in Th17 cells" are represented as a heat map.

In addition, we used the unique ability to access serial ascites samples in patients with ovarian cancer to investigate the effect of infliximab on the ovarian tumor microenvironment. Based on the analysis of the plasma and ascitic samples before and after treatment, we propose that consistent with our murine studies, infliximab (anti-TNF- $\alpha$ ) in malignant disease modulates IL-17 expression in the tumor microenvironment and therefore adds another characteristic to the portfolio of TNF- $\alpha$ 's tumor-promoting actions.

The IL-17 family of proinflammatory cytokines is produced predominantly by Thelper cells (Th17 cells). IL-17 acts in vitro and in vivo as a potent inflammatory cytokine $(40,41)$. It has pleiotropic activities, one of which is to coordinate tissue inflammation by inducing the expression of other proinflammatory cytokines (such as IL-6 and TNF), chemokines (such as KC, MCP-1, and MIP-2), and matrix metalloproteases, which mediate tissue infiltration and tissue destruction (42). The ovarian cancer tumor microenvironment, tumor cells, tumor-derived fibroblasts, macrophages, T cells, and APCs produce high amounts of IL-1, IL-6, IL-23, and TNF- $\alpha$, thus forming a proinflammatory cytokine milieu that facilitates the differentiation and expansion of Th17 cells. Infliximab treatment in our clinical samples decreased IL-6 production in peripheral blood; however, anti-TNF- $\alpha$ had few effects on IL- 6 mRNA expression by CD $4{ }^{+} \mathrm{CD} 25$ - lymphocytes. IL- 6 is produced by other PBMCs, stromal cells in tumors, and also by tumor cells. Therefore, this observation might indicate that anti-TNF- $\alpha$ is sufficient to inhibit IL-6 expression and secretion by cells other than lymphocytes. IL-17 is also involved in the proliferation, maturation, and chemotaxis of neutrophils (43). IL-17-producing $\mathrm{CD}^{+}$cells are present in the human and mouse tumor microenvironment (44) and lack cytotoxic capacity (45). Expression of IL-17 can be detected in sera and target tissues of patients with various autoimmune diseases, including rheumatoid arthritis, multiple sclerosis, and systemic lupus erythematous (41). Information from both human and murine cancers suggests that IL-17 is generally a protumor influence, promoting angiogenesis and fueling the proinflammatory cytokine and chemokine network $(6,44)$.

Recruitment of GR $1^{+}$cells has been previously linked with IL-17 (39). It has been demonstrated that IL-17 can specifically and selectively recruit neutrophils via the release of C-X-C chemokines from the surrounding cells (46). IL-23/IL-17-induced neutrophil recruitment plays a pivotal role in inflammatory diseases; however, the mechanism of the neutrophil recruitment is obscure. Gr-1 antibodies have been successfully used to deplete neutrophils in situ $(39,47)$. The effects observed by depleting Gr-1 $1^{+}$ cells in vivo might be influenced by the fact that circulating murine myeloid cells comprise 2 large subpopulations that are responsible for seeding normal tissues (Gr-1-CCR2-CX3CR1 ${ }^{\text {hi }}$ ) or responding to sites of inflammation $\left(\mathrm{Gr}-1^{+} \mathrm{CCR} 2^{+} \mathrm{CX} 3 \mathrm{CR} 1^{\mathrm{lo}}\right)(48)$. In an inflammatory model of toxoplasmosis, the failure to recruit $\mathrm{Gr}-1^{+}$monocytes resulted in greatly enhanced mortality despite the induction of normal Th1 cell responses leading to high levels of IL-12, TNF- $\alpha$, and IFN- $\gamma$ (48).

We could detect IL-17 in both ovarian cancer ascites and plasma of ovarian cancer patients in our study. This is consistent with previously published data (49) demonstrating that key cytokines are secreted by ovarian tumor cells and tumor-associated antigen-presenting cells that favor the generation and expansion of human Th17 cells. TNF- $\alpha$ and IL-1 have been pro- 
posed to have an additional role in the amplification of Th17 responses $(50,51)$. These findings are consistent with other studies that report that both mouse and human memory $\mathrm{T}$ cells secrete IL-17 in vitro in response to stimulation with IL-1 or IL-23 and either IL-1 $\beta$ or IL-23 could promote the differentiation of human Th17 cells from naive T cells (52-54). Our results suggest that TNF- $\alpha$ promotes Th17 cells by increasing IL-1R and IL-23R expression.

The underlying mechanisms of action for anti-TNF- $\alpha$ therapy have been extensively studied in rheumatoid arthritis and Crohn disease (55-57). The efficacy of infliximab has been attributed to a number of different in vitro mechanisms, including binding of TNF- $\alpha$ and induction of antibody-dependent cellular cytotoxicity, complement activation, and $\mathrm{T}$ cell and macrophage apoptosis that are mediated via the Fc portion of the antibodies $(10,58)$.

In many different experimental and human cancers, malignant cells produce TNF- $\alpha$ during tumor growth and spread (3). Preclinical experiments with TNF- $\alpha$ antagonists and early-phase clinical trials of TNF- $\alpha$ antagonists in patients with advanced cancer suggest that this inflammatory cytokine may be a useful target $(18,36$, 59). Our data demonstrate that IL-17 is certainly involved in the TNF- $\alpha$ microenvironment connection but also show that IL-17 is not the only downstream target of TNF- $\alpha /$ TNFR1 signaling (13, $14,18,33-35)$; IL-17 is therefore a part of the TNF- $\alpha$ network but not solely responsible for its action in disease progression. TNF- $\alpha$ and its receptors are not essential during a strong inflammatory response but are crucial in the regulation of immune responses that occur under conditions of limited immunostimulatory capacity, such as tumor surveillance (60).

There is a caveat to targeting cytokines in cancer therapy. Although inflammation is clearly linked with tumorigenesis, both the innate and adaptive immune systems have the capacity to recognize and eliminate malignant cells (61). Many proinflammatory cytokines may function in tumor immune surveillance, and it is vital to determine whether the function of potential therapeutic targets, such as IL-17, also contributes to antitumor immunity. $\gamma \delta \mathrm{T}$ cell lymphomas have been cited as rare complications of anti-TNF therapy in humans (particular in patients with juvenile Crohn disease) (62); however, complete TNF- $\alpha$ ablation did not change lymphomagenesis in $p 53^{-/-}$and $p 53^{+/-}$mice (63). In addition, TNF- $\alpha$, IL-1, and IL- 6 have critical roles in host defense in both the innate and adaptive immune systems.

In rheumatoid arthritis patients treated with TNF- $\alpha$ antagonists, the risks of infection and cancer are still being assessed, but on the basis of current information it can be said that (a) there is an increased risk of serious infection ( 2 -fold); (b) vigilance is required for tuberculosis and other granulomatous and intracellular infection when screening patients, as well as close monitoring thereafter; and (c) there is no overall increased cancer risk, but there are concerns regarding skin cancers and possible greater risks of recurrence for patients with prior tumors (62).

The full potential of these anticytokine agents in cancer therapy may only be realized in combination with tolerable regimes of existing chemotherapy or with other agents such as inhibitors of angiogenesis that modify the tumor microenvironment. Further mechanistic studies on the role of cytokines in carcinogenesis will undoubtedly reveal new potential targets with increased efficacy and reduced side effects. The challenge now is to identify a rationale for which combinations will be most effective in which patients. The results presented in this study show the potential of inhibiting cancer-related inflammation, and it is hoped that future studies with more defined combinations will produce more sustained clinical responses.

\section{Methods}

Mice, cell lines, and reagents. CD4-Cre, CD19-Cre (64), LysM-Cre (65), TNFR1 $1^{--}$, TNFR2 $2^{--}$, TNFR $1 / 2^{-/-}$, and TNFR $1^{\text {flcneo }}$ (37) mice were maintained on a C57BL/ 6 genetic background. TNFR1 expression (floxed) is inhibited by the presence of the neomycin cassette but is restored upon Cre-mediated neo excision. TNFR $1^{\text {flcneo }}$ mice were crossed with LysM-Cre, CD4-Cre, or CD19-Cre mice to generate mice with functional TNFR1 expression in myeloid cells (TNFR1 $\Delta$ LysM), CD4 ${ }^{+} \mathrm{T}$ cells (TNFR1 $\left.\Delta \mathrm{CD} 4\right)$, or B cells (TNFR1 $\triangle$ CD19). To assess the Cre-mediated excision of the floxed neo cassette and the subsequent activation of TNFR1 expression in $\mathrm{CD}^{+}, \mathrm{CD}_{19} 9^{+}$, or $\mathrm{LysM}^{+}$cells, we used sequential MACS separation and FACS sorting to isolate $\mathrm{CD}^{+}, \mathrm{CD} 19^{+}$, or $\mathrm{CD} 11 \mathrm{~b}^{+}$cells to $95 \%$ purity. PCR analysis of DNA has been carried out as described before to demonstrate efficient Cre-mediated recombination (37). The efficiency of recombination was measured by FACS analysis, showing between $75 \%$ and $96 \%$ recombination in the respective lineage.

All mice were maintained in the Biological Services Unit, Institute of Cancer, Barts and the London School of Medicine, and used according to established institutional guidelines under the authority of a UK Home Office project license (Guidance on the Operation of Animals [Scientific Procedures] Act 1986); all animal studies were approved by the UK Home Office. CD4-Cre and CD19-Cre mice were a gift from Sergei Nedospasov, Engelhardt Institute of Molecular Biology, Russian Academy of Sciences, Moscow, Russia.

Eight-week-old C57BL/ 6 female mice were injected i.p. with $1 \times 10^{7}$ ID8luc cells. Tumor burden was assessed weekly in situ by bioluminescence imaging. Mice were treated twice weekly with a monoclonal antibody that inhibits murine TNF- $\alpha$ (CNTO5048, provided by Centocor) or a nonspecific IgG control (CNTO1322, provided by Centocor) i.p. (50 $\mu \mathrm{g} / \mathrm{mouse})$ for 8 weeks. Experiments were repeated twice $(n=60)$. For IL-17 neutralization, mice were injected twice weekly with a monoclonal antibody that inhibits murine IL-17A (clone eBioMM17F3; eBioscience) or a respective IgG1 control (100 $\mu \mathrm{g} /$ mouse; eBioscience).

For depletion of Gr-1+ $1^{+}$cells in vivo, Gr-1 mAb (RB6-8C5, $100 \mu \mathrm{g} /$ mouse; eBioscience) or IgG control (CNTO1322) was injected i.p. twice weekly.

Recombinant mouse IL-17A (rmIL-17; R\&D Systems) was diluted in sterile endotoxin-free PBS and administered i.p. at a dose of $0.5 \mu \mathrm{g} /$ mouse in a total volume of $100 \mu \mathrm{l}$. The concentration of IL-17A to be applied was determined in preliminary dose-response experiments, which showed that $0.5 \mu \mathrm{g}$ IL-17A consistently produced a significant influx of neutrophils (data not shown). Control animals received an equivalent volume of PBS alone.

Adoptive transfer. TNFR1 $1^{-/}$, TNFR2 $2^{-/}$, or WT mice on the C57BL/6 background were irradiated by giving a single absorbed dose of 10 Gy to the whole body using a linear accelerator with $15 \mathrm{MV}$ nominal photon energy and a dose rate of $3.6 \mathrm{~Gy} / \mathrm{min}$. After irradiation, mice were rested for 4 to 6 hours and thereafter reconstituted by i.v. injection with $5 \times 10^{6}$ bone marrow cells isolated from TNFR1 $1^{--}$, TNFR2 $2^{--}$, or WT mice. All mice were given water containing $0.56 \mathrm{mg} / \mathrm{ml}$ of enrofloxacin (Baytril) for 4 weeks after irradiation to minimize the risk of infection. After transplantation, the animals were maintained in individually ventilated microisolator cages on sterilized food and acidified sterile water. Adoptive transfer of macrophages was conducted as described before (28).

Tumor assessment. Tumor progression was assessed in situ by bioluminescent imaging as described previously (20). The murine ovarian cancer cell line, ID8, a gift from Kathy Roby (University of Kansas Medical Center, Kansas City, Kansas, USA) (66), was cultured as previously described 
(67). Lentiviral infection of ID8 cells with luciferase reporter construct was performed as described before (20). Ascitic cells were counted using a hemocytometer; mice presented with approximately $10 \mathrm{ml}$ of ascites at the end of the experiment. Cytospins were prepared from $500 \mu \mathrm{l}$ of ascitic fluid, and cells were differentiated with Wright's staining.

$\mathrm{CD} 4^{+}$T cell purification. $\mathrm{CD} 4^{+} \mathrm{T}$ cells $\left(\mathrm{CD} 4^{+} \mathrm{CD} 25^{-}\right)$were purified by FACS sorting following a MACS bead isolation of $\mathrm{CD}^{+}$cells for mRNA isolation. Naive $\mathrm{CD} 4^{+} \mathrm{T}$ cells $\left(\mathrm{CD} 4^{+} \mathrm{CD} 25^{-}\right)$were selected from peripheral blood of healthy blood donors. Murine $\mathrm{CD} 4^{+} \mathrm{T}$ cells $\left(\mathrm{CD} 4^{+} \mathrm{CD} 25^{-}\right)$were purified by MACS bead isolation from spleens. $5 \times 10^{6} \mathrm{CD} 4^{+} \mathrm{CD} 25^{-} \mathrm{T}$ cells from TNFR1 $1^{--}$, TNFR2 $2^{--}$, and TNFR1/2-/- mice were stimulated with $100 \mathrm{ng}$ of recombinant murine TNF- $\alpha$ (R\&D Systems) for 6 hours, followed by mRNA isolation for IL-1R and IL-23R expression.

Flow cytometry. FACS analysis was performed on a FACScan flow cytometer and analyzed using Cellquest software (BD). Ascitic T cell populations were enriched prior to analysis using R\&D Systems $T$ cell enrichment columns.

ELISA-based assays. Human and murine plasma and ascites TNF- $\alpha$, IL-1, IL-4, IL-6, IL-17, IL-17F, IL-22, IL-23, CCL2, CCL5, and TGF- $\beta$ concentrations were measured using commercially available ELISA kits according to manufacturer's instructions (all R\&D Systems). Human IL-21 ELISA was purchased from eBioscience.

Real-time RT-PCR analysis. RNA was extracted from snap-frozen ascitic cell pellets using TRI Reagent (Sigma-Aldrich) according to the manufacturer's protocol. Only samples with OD 260:280 ratios of greater than 1.8 were used for cDNA synthesis. RNA $(2 \mu \mathrm{g})$ was reverse transcribed into $100 \mu \mathrm{l}$ cDNA using the Moloney murine leukemia virus reverse transcriptase and random hexamers (Promega). cDNA was analyzed by real-time analysis using the ABI PRISM 7700 Sequence Detection System instrument and software (PE Applied Biosystems). Probes with the following Applied Biosystems assay identification numbers were used: human: retinoic acid-related orphan receptor C (RORC), Hs01076112_m1; IL1RA, Hs00991008_m1; IL23R, Hs01001361_m1; IL6, Hs00174131_m1; IL17, Hs00174383_m1; IL22, Hs00220924_m1; IFNG, Hs00989291_m1; CCR4, Hs00356611_s1; CCR6, Hs00171121_m1; murine: Il17, Mm00439619_ m1; Il1ra, Mm01226963_m1; Il23r, Mm01186169_m1; and Ifng, Mm99999071_m1.

Because a RORC-specific probe was not available and the RORC long variant (assay identification number Hs00172858_m1; Applied Biosystems) was not detected in any of the conditions tested (data not shown), we quantified retinoic acid-related orphan receptor C isoform 2 (RORC2) mRNA with a probe (assay identification number Hs01076112_m1; Applied Biosystems) that recognizes retinoic acid-related orphan receptor $\gamma$-specific (ROR $\gamma$-specific) and retinoic acid-related orphan receptor $\gamma$ $\mathrm{t}$-specific (ROR $\gamma \mathrm{t}-$ specific) mRNA as described before (68). For each sample, mRNA abundance was normalized to the amount of $18 \mathrm{~S}$ rRNA and is expressed as arbitrary units.

Patients and clinical trial design. We used patient samples from 2 clinical trials. The first phase I/II trial was a single-center trial and conducted with 41 patients with advanced malignant disease (36) (40 sufficient samples for analysis). This second phase I/II trial was a single-center, open-label, study of infliximab at 2 dose levels $(5 \mathrm{mg} / \mathrm{kg}$ and $10 \mathrm{mg} / \mathrm{kg})$ in 17 patients with advanced epithelial ovarian cancer (15 sufficient samples for analysis). Patients received infliximab as a 2 -hour i.v. infusion on weeks 0,2 , and 6 (indicated timing started from the end of the infusion). Doses and schedule of infliximab treatment in this trial were based on the previous phase I trials in other inflammatory diseases (36). Three control patients requiring ascitic drainage but treated with infliximab were also enrolled in the trial. These patients did not receive infliximab but underwent the same paracentesis procedure as the treated patients. The ascitic fluid samples were analyzed to determine the effect of drainage on changes within the tumor microenvironment. A complete patient history and examination were performed at baseline and before each course of treatment. Full blood counts, electrolytes, and blood chemistries were performed weekly. Clinical tumor measurement and radiological assessments were carried out at study entry and at the off-study visit (4 weeks after last infusion). Clinical sample preparation and experimental methods with these samples are presented in Supplemental Methods.

Ethical considerations. The study was approved by the North East London and the City Health Authority Research Ethics Committee (LREC $\mathrm{P} / 02 / 150$ ) and the Lothian Research Ethics Committee (LREC2000/4/60, LREC/2002/8/31) and conducted according to the declaration of Helsinki. All patients gave voluntary, written informed consent.

Ranking of ovarian cancer microarray samples for inflammatory pathways using GSEA. The microarray data set GSE9899 was downloaded from the GEO website (http:/www.ncbi.nlm.nih.gov/geo) and analyzed using Bioconductor 1.9 (http://www.bioconductor.org) running on R 2.8.0 (69). Probeset expression measures were calculated using the Affymetrix package's robust multichip average (RMA) default method (70). The inflammatory gene set of TNF- $\alpha$ canonical signaling pathway was extracted from GeneGo's Metacore pathway analysis tool (GeneGo Inc.). The function GeneSetTest from the limma package (71) was used to assess whether each sample had a tendency to be associated with an up- or downregulation of members of the TNF- $\alpha$ pathway. The function employs Wilcoxon's $t$ test to generate $P$ values. All samples were ranked on this enrichment, from most significant to least significant. The top and bottom 50 samples were extracted from the data set and given the names of "high TNF- $\alpha$ " and "low TNF- $\alpha$ " respectively.

Gene set enrichment using Metacore pathway and process gene set. Differentially expressed probes between the high-TNF- $\alpha$ and low-TNF- $\alpha$ groups were selected based on meeting a criteria of false discovery rate of less than 0.05 . Probes were divided into positive and negative fold change lists and used to determine enrichment using GeneGo processes within the Metacore pathway tool. The analysis employs a hypergeometric distribution to determine the most enriched gene set. Genes that were differentially expressed in "cytokine production in Th17 cells" were used to generate a heat map using Java Cluster. Colors indicate probeset expression level relative to the median across the top and bottom 50 ovarian cancer samples.

Statistics. Experiments were performed as indicated (duplicate or triplicate), and representative data are shown. Results were tested for statistical significance using 2-tailed Student's $t$ test with Welch's correction or Mann-Whitney test with GraphPad Prism Version 4.0c software. $P<0.05$ was considered significant.

\section{Acknowledgments}

We thank Katherine Li, Robert E. Corringham, Marian T. Nakada, Mark DeWitte, and Renu Vora at Centocor (Centocor R\&D Inc., Malvern, Pennsylvania, USA) for their help and support in conducting the clinical trial and data analysis. We also thank Diane Scott, Rhona E. Aird, Moira Stewart, and Ron L. Rye at the University of Edinburgh, Cancer Research Centre, for their help in the PH28 and O24 study and sample collection.CD4-Cre and CD19-Cre mice were a kind gift from Sergei Nedospasov, Engelhardt Institute of Molecular Biology, Russian Academy of Sciences, Moscow, Russia. This research was supported by grants from the Medical Research Council (to T. Hagemann and R. Soper), Cancer Research UK (to T. Hagemann, H. Kulbe, and F.R. Balkwill), Ovarian Cancer Action (to T. Hagemann and M. Escorcio-Correia), Charitable Foundation of Bart's and The London School of Medicine and Dentistry (to T. Hagemann, K.A. Charles, and R. Soper), Centocor Inc. (to K.A. Charles), and Higher Education Funding Council for England (to F.R. Balkwill). 
Received for publication February 7, 2009, and accepted in revised form July 15, 2009.

Address correspondence to: Thorsten Hagemann, Centre for Cancer and Inflammation, Institute of Cancer and CR-UK Clinical Cancer Centre, Barts and The London School of Medicine and Dentistry, Queen Mary University of London, John Vane Sci- ence Centre, Charterhouse Square, London EC1M 6BQ, United Kingdom. Phone: 44-20-78825795; Fax: 44-20-78826110; E-mail: t.hagemann@qmul.ac.uk.

K.A. Charles's present address is: Discipline of Pharmacology, Faculty of Medicine, and Bosch Institute, University of Sydney, Sydney, New South Wales, Australia.
1. Mantovani, A., Allavena, P., Sica, A., and Balkwill, F. 2008. Cancer-related inflammation. Nature. 454:436-444.

2. McInnes, I.B., and Schett, G. 2007. Cytokines in the pathogenesis of rheumatoid arthritis. Nat. Rev. Immunol. 7:429-442.

3. Balkwill, F. 2006. TNF-alpha in promotion and progression of cancer. Cancer Metastasis Rev. 25:409-416.

4. Hodge, D.R., Hurt, E.M., and Farrar, W.L. 2005. The role of IL- 6 and STAT3 in inflammation and cancer. Eur. J. Cancer. 41:2502-2512.

5. Naugler, W.E., et al. 2007. Gender disparity in liver cancer due to sex differences in MyD88-dependent IL-6 production. Science. 317:121-124.

6. Numasaki, M., et al. 2003. Interleukin-17 promotes angiogenesis and tumor growth. Blood. 101:2620-2627.

7. Langowski, J.L., et al. 2006. IL-23 promotes tumour incidence and growth. Nature. 442:461-465.

8. Sredni, B., et al. 2004. Ammonium trichloro-(dioxoethylene-o,o')tellurate (AS101) sensitizes tumors to chemotherapy by inhibiting the tumor interleukin 10 autocrine loop. Cancer Res. 64:1843-1852.

9. Derynck, R., Akhurst, R.J., and Balmain, A. 2001. TGF-beta signaling in tumor suppression and cancer progression. Nat. Genet. 29:117-129.

10. Feldmann, M., and Maini, S.R. 2008. Role of cytokines in rheumatoid arthritis: an education in pathophysiology and therapeutics. Immunol. Rev. 223:7-19.

11. Moore, R.J., et al. 1999. Mice deficient in tumor necrosis factor-alpha are resistant to skin carcinogenesis. Nat. Med. 5:828-831.

12. Pikarsky, E., et al. 2004. NF-kappaB functions as a tumour promoter in inflammation-associated cancer. Nature. 431:461-466.

13. Popivanova, B.K., et al. 2008. Blocking TNF-alpha in mice reduces colorectal carcinogenesis associated with chronic colitis. J. Clin. Invest. 118:560-570.

14. Egberts, J.H., et al. 2008. Anti-tumor necrosis factor therapy inhibits pancreatic tumor growth and metastasis. Cancer Res. 68:1443-1450.

15. Yang, H., et al. 2006. TNF-alpha inhibits asbestosinduced cytotoxicity via a NF-kappaB-dependent pathway, a possible mechanism for asbestosinduced oncogenesis. Proc. Natl. Acad. Sci. U. S. A. 103:10397-10402.

16. Balkwill, F. 2009. Tumor necrosis factor and cancer. Nat. Rev. Cancer. 9:361-371.

17. Davies, B., et al. 1993. Activity of type IV collagenases in benign and malignant breast disease. $\mathrm{Br}$. J. Cancer. 67:1126-1131.

18. Harrison, M.L., et al. 2007. Tumor necrosis factor alpha as a new target for renal cell carcinoma: two sequential phase II trials of infliximab at standard and high dose. J. Clin. Oncol. 25:4542-4549.

19. Galban, S., et al. 2003. von Hippel-Lindau proteinmediated repression of tumor necrosis factor alpha translation revealed through use of cDNA arrays. Mol. Cell. Biol. 23:2316-2328.

20. Kulbe, H., et al. 2007. The inflammatory cytokine tumor necrosis factor-alpha generates an autocrine tumor-promoting network in epithelial ovarian cancer cells. Cancer Res. 67:585-592.

21. Stathopoulos, G.T., et al. 2007. Tumor necrosis factor-a promotes malignant pleural effusion. Cancer Res. 67:9825-9834.

22. Petersen, S.L., et al. 2007. Autocrine TNFa signaling renders human cancer cells susceptible to Smacmimetic-induced apoptosis. Cancer Cell. 12:445-456.

23. Zins, K., Abraham, D., Sioud, M., and Aharinejad, S. 2007. Colon cancer cell-derived tumor necrosis factor-a mediates the tumor growth-promoting response in macrophages by up-regulating the colony-stimulating factor-1 pathway. Cancer Res. 67:1038-1045.

24. Bates, R.C., and Mercurio, A.M. 2003. Tumor necrosis factor- $\alpha$ stimulates the epithelial-to-mesenchymal transition of human colonic organoids. Mol. Biol. Cell. 14:1790-1800.

25. Yan, B., et al. 2006. Tumor necrosis factor-a is a potent endogenous mutagen that promotes cellular transformation. Cancer Res. 66:11565-11570.

26. Li, B., et al. 2009. Low levels of tumor necrosis factor alpha increase tumor growth by inducing an endothelial phenotype of monocytes recruited to the tumor site. Cancer Res. 69:338-348.

27. Elgert, K.D., Alleva, D.G., and Mullins, D.W. 1998. Tumor-induced immune dysfunction: the macrophage connection. J. Leukoc. Biol. 64:275-290.

28. Hagemann, T., et al. 2008. "Re-educating" tumorassociated macrophages by targeting NF-kappaB. J. Exp. Med. 205:1261-1268.

29. Tomita, Y., et al. 2004. Spontaneous regression of lung metastasis in the absence of tumor necrosis factor receptor p55. Int. J. Cancer. 112:927-933.

30. Kitakata, H., et al. 2002. Essential roles of tumor necrosis factor receptor p55 in liver metastasis of intrasplenic administration of colon 26 cells. Cancer Res. 62:6682-6687.

31. Arnott, C.H., et al. 2004. Expression of both TNFalpha receptor subtypes is essential for optimal skin tumour development. Oncogene. 23:1902-1910.

32. Chen, X., Baumel, M., Mannel, D.N., Howard, O.M., and Oppenheim, J.J. 2007. Interaction of TNF with TNF receptor type 2 promotes expansion and function of mouse CD4+CD25+ T regulatory cells. J. Immunol. 179:154-161.

33. Scott, K.A., et al. 2003. An anti-tumor necrosis factoralpha antibody inhibits the development of experimental skin tumors. Mol. Cancer Ther. 2:445-451.

34. Madhusudan, S., et al. 2004. A phase II study of Etanercept (Enbrel), a tumour necrosis factor-a inhibitor in patients with metastatic breast cancer. Clin. Cancer Res. 10:6528-6534.

35. Madhusudan, S., et al. 2004. A phase II study of etanercept (ENBREL), a tumor necrosis factoralpha inhibitor in patients with metastatic breast cancer. Clin. Cancer Res. 10:6528-6534.

36. Brown, E.R., et al. 2008. A clinical study assessing the tolerability and biological effects of infliximab, a TNF-alpha inhibitor, in patients with advanced cancer. Ann. Oncol. 19:1340-1346.

37. Victoratos, P., et al. 2006. FDC-specific functions of P55TNFR and IKK2 in the development of FDC networks and of antibody responses. Immunity. 24:65-77.

38. Moseley, T.A., Haudenschild, D.R., Rose, L., and Reddi, A.H. 2003. Interleukin-17 family and IL-17 receptors. Cytokine Growth Factor Rev. 14:155-174.

39. Witowski, J., et al. 2000. IL-17 stimulates intra-peritoneal neutrophil infiltration through the release of GRO alpha chemokine from mesothelial cells. J. Immunol. 165:5814-5821.

40. Bettelli, E., Korn, T., Oukka, M., and Kuchroo, V.K. 2008. Induction and effector functions of $\mathrm{T}(\mathrm{H}) 17$ cells. Nature. 453:1051-1057.

41. Bettelli, E., Oukka, M., and Kuchroo, V.K. 2007. $\mathrm{T}(\mathrm{H})-17$ cells in the circle of immunity and autoimmunity. Nat. Immunol. 8:345-350.

42. Kolls, J.K., and Linden, A. 2004. Interleukin-17 family members and inflammation. Immunity. 21:467-476.

43. Fossiez, F., et al. 1996. T cell interleukin-17 induces stromal cells to produce proinflammatory and hematopoietic cytokines. J. Exp. Med. 183:2593-2603.

44. Kryczek, I., et al. 2007. Cutting edge: Th17 and regulatory $\mathrm{T}$ cell dynamics and the regulation by IL-2 in the tumor microenvironment. J. Immunol. 178:6730-6733.

45. Liu, S.J., et al. 2007. Induction of a distinct CD8 Tnc17 subset by transforming growth factor-beta and interleukin-6. J. Leukoc. Biol. 82:354-360.

46. Laan, M., et al. 1999. Neutrophil recruitment by human IL-17 via C-X-C chemokine release in the airways. J. Immunol. 162:2347-2352.

47. Rodriguez, N., et al. 2005. Polymorphonuclear neutrophils improve replication of Chlamydia pneumoniae in vivo upon MyD88-dependent attraction. J. Immunol. 174:4836-4844.

48. Robben, P.M., LaRegina, M., Kuziel, W.A., and Sibley, L.D. 2005. Recruitment of Gr-1+ monocytes is essential for control of acute toxoplasmosis. J. Exp. Med. 201:1761-1769.

49. Miyahara, Y., et al. 2008. Generation and regulation of human CD4+ IL-17-producing T cells in ovarian cancer. Proc. Natl. Acad. Sci. U. S. A. 105:15505-15510.

50. Veldhoen, M., Hocking, R.J., Atkins, C.J., Locksley, R.M., and Stockinger, B. 2006. TGFbeta in the context of an inflammatory cytokine milieu supports de novo differentiation of IL-17-producing T cells. Immunity. 24:179-189.

51. Sutton, C., Brereton, C., Keogh, B., Mills, K.H., and Lavelle, E.C. 2006. A crucial role for interleukin (IL)-1 in the induction of IL-17-producing T cells that mediate autoimmune encephalomyelitis. J. Exp. Med. 203:1685-1691.

52. Aggarwal, S., Ghilardi, N., Xie, M.H., de Sauvage, F.J., and Gurney, A.L. 2003. Interleukin-23 promotes a distinct CD4 $\mathrm{T}$ cell activation state characterized by the production of interleukin-17. J. Biol. Chem. 278:1910-1914.

53. van Beelen, A.J., et al. 2007. Stimulation of the intracellular bacterial sensor NOD2 programs dendritic cells to promote interleukin-17 production in human memory $\mathrm{T}$ cells. Immunity. 27:660-669.

54. Wilson, N.J., et al. 2007. Development, cytokine profile and function of human interleukin 17-producing helper T cells. Nat. Immunol. 8:950-957.

55. Charles, P., et al. 1999. Regulation of cytokines, cytokine inhibitors, and acute-phase proteins following anti-TNF-alpha therapy in rheumatoid arthritis. J. Immunol. 163:1521-1528.

56. Baert, F., et al. 2003. Influence of immunogenicity on the long-term efficacy of infliximab in Crohn's disease. N. Engl. J. Med. 348:601-608.

57. Maini, R.N., and Taylor, P.C. 2000. Anti-cytokine therapy for rheumatoid arthritis. Annu. Rev. Med. 51:207-229.

58. Notley, C.A., et al. 2008. Blockade of tumor necrosis factor in collagen-induced arthritis reveals a novel immunoregulatory pathway for Th1 and Th17 cells. J. Exp. Med. 205:2491-2497. 
59. Balkwill, F. 2009. Tumour necrosis factor and cancer. Nat. Rev. Cancer. 9:361-371.

60. Calzascia, T., et al. 2007. TNF-alpha is critical for antitumor but not antiviral $\mathrm{T}$ cell immunity in mice. J. Clin. Invest. 117:3833-3845.

61. Dranoff, G. 2004. Cytokines in cancer pathogenesis and cancer therapy. Nat. Rev. Cancer. 4:11-22.

62. Askling, J., and Bongartz, T. 2008. Malignancy and biologic therapy in rheumatoid arthritis. Curr. Opin. Rheumatol. 20:334-339.

63. Kuprash, D.V., et al. 2008. Ablation of TNF or lymphotoxin signaling and the frequency of spontaneous tumors in p53-deficient mice. Cancer Lett. 268:70-75.
64. Grivennikov, S.I., et al. 2005. Distinct and nonredundant in vivo functions of TNF produced by $t$ cells and macrophages/neutrophils: protective and deleterious effects. Immunity. 22:93-104.

65. Clausen, B.E., Burkhardt, C., Reith, W., Renkawitz, R., and Forster, I. 1999. Conditional gene targeting in macrophages and granulocytes using LysMcre mice. Transgenic Res. 8:265-277.

66. Roby, K.F., et al. 2000. Development of a syngeneic mouse model for events related to ovarian cancer. Carcinogenesis. 21:585-591.

67. Hagemann, T., et al. 2006. Ovarian cancer cells polarize macrophages toward a tumor-associated phenotype. J. Immunol. 176:5023-5032.
68. Acosta-Rodriguez, E.V., et al. 2007. Surface phenotype and antigenic specificity of human interleukin 17-producing T helper memory cells. Nat. Immunol. 8:639-646.

69. Gentleman, R.C., et al. 2004. Bioconductor: open software development for computational biology and bioinformatics. Genome Biol. 5:R80.

70. Gautier, L., Cope, L., Bolstad, B.M., and Irizarry, R.A. 2004. affy--analysis of Affymetrix GeneChip data at the probe level. Bioinformatics. 20:307-315.

71. Smyth, G.K. 2004. Linear models and empirical bayes methods for assessing differential expression in microarray experiments. Stat. Appl. Genet. Mol. Biol. 3:Article3. 